\title{
Spillover effect of United States Monetary Policy on Nigeria's Financial and Macro Fundamentals
}

\section{Patterson C. Ekeocha ${ }^{1}$ and Elias A. Udeaja ${ }^{2}$}

This paper examines spillover effects of U.S monetary policy on macroeconomic fundamentals in Nigeria from January 1985 to December 2018. The study period is partitioned to account for conventional monetary policy (CMP) period, January 1985 to August 2007 and unconventional monetary policy (UMP) period, September 2007 to December 2018. Guided by relevant pre-tests, we find BEKK-VARMA-CCCMGARCH as the most appropriate model. The study finds significant spillover effects of U.S CMP and UMP on interest rate, exchange rate and inflation rate in Nigeria. We, however, observe that while CMP may be a significant accelerator of shocks persistence on interest rates and exchange rates, the extent to which the UMP accelerate shocks in inflation rate tends to vary for different measures of quantitative easing. Thus, in addition to past own shocks and past own conditional variance of these macro fundamentals, understanding their dynamics cannot be in isolation of their vulnerability to external shocks and volatility due to spillover effects of monetary actions in other economies. In formulating monetary policy, it is therefore, imperative for the Central Bank of Nigeria to monitor the monetary policy process of the US to hedge against shocks spillovers.

Keywords: Foreign Monetary Policy; Shock Persistence; Spillover Effect; US-Nigeria; VARMA-MGARCH

JEL Classification: E52, E58, F37, F42

DOI: $10.33429 /$ Cjas.11120.5/5

\section{Introduction}

It is a common knowledge that the global economy is fast becoming more connected with international trade being a major underlying source of such connectivity. It is adjudged that any shock to US monetary policy is likely to have considerable spillover effects on the rest of the world due to its influence (Landau, 2013). The potential of such spillover effects can be attributed to the huge international trade volume of the US coupled with her robust financial markets and her enormous foreign direct investment activities. Reaffirming this is

\footnotetext{
${ }^{1}$ Corresponding Author: patterson.ekeocha@gmail.com; pcekeocha@cbn.gov.ng

2 eudeaja@gmail.com; eaudeaja@cbn.gov.ng

Authors are staff of Research Department, Central Bank of Nigeria.

The views expressed in this paper are those of the authors and do not necessarily represent those of the Central Bank of Nigeria.
} 
the business cycle that follows the global financial crisis demonstrating how sensitive the world economy is, to changes in US monetary policy. Most countries irrespective of their exchange rate regime can be potentially vulnerable to changes in U.S monetary policy. The aftermath of the recent global financial crisis (GFC) is a typical epitome of the consequence of what occurred in the US, including innovations in its monetary policy on economies that have direct or indirect trade and capital transaction with US (see Chen at al., 2016; Chin, 2013).

Nigeria as at 2018 was the US 49th largest goods trading partner with goods export totaled $\$ 2.7$ billion and goods import totaled $\$ 5.6$ billion, while the US goods trade deficit with Nigeria was put at $\$ 3.0$ billion over the same period of time. ${ }^{3}$ Even as at 2017 , the US goods and services trade with Nigeria totaled $\$ 12.1$ billion and considered significant. The US foreign direct investment (FDI) in Nigeria in terms of stock was \$61 million dollars as at 2017 constituting 48.8 per cent increase when compared to the value for $2016 .{ }^{4}$ These among others, strongly position Nigeria as potentially susceptible to developments in the US. Invariably, it is only rational to assume that what affects economic activities in the US economy is likely to have a spillover effects on economic activities in Nigeria.

Notable among the indicators for measuring economic activities around the world include financial and macro fundamentals such as interest rate, inflation rate and exchange rate. Shocks to any of these fundamentals usually prompt a monetary policy reaction, thus portending possibility of spillover effects of monetary policy shock from one economy to another economy, particularly for economies that are connected via trade such as US and Nigeria. There has been an extensive body of work that examines different aspects of the role of the US economy and the global spillover it generates. However, in addition to the relatively dearth of literature for the case of developing economies such as Nigeria, a number of the extant studies have continued to describe monetary policy mainly from the conventional perspective (see Iacoviello and Navarro 2018; Kose et al, 2017; Ammer et al., 2016; Shuairu and Hamori, 2016; Hajek and Horvath, 2015; Chen, et al., 2014b; Colombo, 2013; Chinn, 2013; Beaton and Brigitte, 2011;Bayoumi and Andrew, 2009; Ehrmann and Fratzscher, 2004).

However, not only has the 2007-2009 U.S subprime mortgage crises had a major impact on

\footnotetext{
${ }^{3}$ See https://ustr.gov/countries-regions/africa/nigeria

${ }^{4}$ See https://ustr.gov/countries-regions/africa/nigeria
} 
the formulation and implementation of monetary policy, the Federal Reserve lowered the federal funds rate target rapidly to near zero and took additional measures considered to be unconventional (see Chen et al., 2015). The unconventional policy actions as embarked upon by the Federal Reserve and other central banks though motivate new strand of literature, but the majority of the studies mainly focused on its domestic effects. Being one of the leading economies in Africa with strong trade relationship with the U.S, Nigeria therefore, is an appropriate choice as case study to investigate the spillover effects of U.S monetary policy on Nigeria. Evidence-based understanding of the monetary policy spillovers associated with the recent unconventional policy activity in the US will help policymakers to cope with the challenges posed by such policies should there be a repeat, and to assess the need for international policy coordination if necessary.

The objective of this study is to examine the spillover effect of US monetary policy on interest rate, exchange rate and inflation rate in Nigeria. To achieve this objective, first, we consider the probable cross-border spillover effects of US monetary policy on macroeconomic fundamentals from both the conventional and unconventional perspectives. Second, we consider alternative measures of quantitative easing to determine the extent to which the spillover effects of the unconventional monetary policy are sensitive to the choice of indicators. Finally, the study captures both shocks and volatility spillover simultaneously following a careful but thorough procedure to understand the inherent feature of the time series under consideration.

The rest of the paper is organized as follows: Section two presents brief literature review on the subject matter. Section three contains the model and estimation techniques. Section four presents the results and discusses the findings. Section five concludes the study with potential policy implications.

\section{Literature Review}

\subsection{Theoretical Framework}

\subsubsection{The Conventional Perspective}

From the conventional monetary policy point of view, there are three basic channels upon which monetary policy intervention in one country can affect economic activities of other countries (Ammer et al., 2016). The first is the exchange rate "transmission channel" of monetary policy shocks to another country based on the famous ISLM-BP model developed 
by Mundell (1963) and Fleming (1962). Supporting this approach is the Taylor rule prediction of specific role for exchange rate as a key transmission of spillovers of foreign monetary policy to the operation of monetary policy in another economy (Taylor, 2001, 2007). In addition to the exchange rate channel, the other two channels of transmission are domestic demand channel and financial spillover demand channel.

Both of the latter mentioned though have expenditure-increasing effects on foreign economies. In the case of the domestic demand channel however, it is predicted that when monetary policy is eased, it leads to increase in domestic demand - that is, spending on consumption and investment - in the home country, which increases home-country imports and thus foreigncountry exports. This domestic demand channel boosts foreign GDP. The other channel, which we refer to as the "financial spillovers" channel, is usually explored when economies are financially integrated with easing monetary policy shock in the source country expected to lower long-term interest rate but gives rise to increase in asset prices in the source country. It is instructive that none of these channels provide clear cut answer to whether expansionary monetary policy in the source country will lead to negative spillover effects on the economic activities of the partner country. To put it differently, none of these channels fits all; instead the probable outcome of a spillover effect of monetary policy depends not only on the strength of the exchange rate channel but also on the joint strength of the domestic demand and financial spillovers channels.

\subsubsection{The Unconventional Perspective}

The implementation of unconventional monetary policy instruments has been the most significant shift in the practice of central banks at the wake of 2007/08 GFC period, particularly in the developed world. However, the evaluation of the spillover effects of the unconventional monetary actions from the source country say US to emerging or developing countries may not be feasible without establishing the channels of the transmission of the spillover effects. According to Chen et al. (2014), Landau (2013) and Ehrmann et al. (2011), there are three channels through which unconventional monetary policy spillover to developing countries can be explored. These channels have been outlined in the context of macroeconomic, behavioural and financial.

Starting with the macroeconomic channels, they are rooted on the increasing integration of trade, capital and banking ties between developing economies and developed countries. The 
macroeconomic channels in this light mostly operate through the effects of monetary policy shocks in the developed countries often informed by domestic conditions in the developed countries. For instance, by raising demand in the developed economies, it also raises imports of goods and services from developing countries tied by trade links. Similar to this is the exchange rate channel in the case of conventional monetary policy. Regarding the behavioral channels of the transmission mechanism of spillover effects of unconventional monetary policy, it is usually attributed to confidence, risk-taking, signaling and sentiment (see Janus, 2015). The operation of the behavioural channels following Bartkiewicz (2018) are preconditioned on the ability of conventional monetary policy to influence the behavior of relevant economic agents and their willingness to spend, take risk or invest (therefore, on central bank credibility).

The third approach to evaluating the spillover effects of unconventional monetary policy in developed countries on the economy of the developing countries is the financial channels associated with asset prices and the effect of their changes. This however, depends on the degree of financial integration between the concern economies. Over the years, financial markets in developing countries such as Nigeria has evolved in terms of both sophistication and interconnectedness with the global financial system. The level of development has improved considerably, and it is expected to respond to major external monetary policy shocks such as the Fed's monetary policy normalization (i.e. quantitative easing (QE)). This increasing integration of the global financial markets is an indication that developing economies such as Nigeria are potentially vulnerable to spillover effects of monetary policy, particular via shocks emanating from the financial markets interconnected to the US economy.

\subsection{Empirical Literature}

Prior to the 2008 GFC, the vast of the extant literature on the cross-border spillover effects of monetary policy mainly focused on the conventional approach to conducting monetary policy (see for example, Iacoviello and Navarro 2018; Kose et al, 2017; Ammer et al., 2016; Shuairu and Shigeyuki, 2016; Chenet al., 2015; Hajek and Horvath, 2015; Chen, et al., 2014a; Colombo, 2013; Chinn, 2013; Beaton and Desroches, 2011; Bayoumi and Adrew, 2009).Considering the severity of the recent 2007/2008 GFC, the literature has been further revisited to understand the extent to which the recently increasing use of the unconventional monetary policy tools matter for the degree of the spillover effects of cross-border monetary 
action (see for example, Apostolou and Beirne, 2019; Punzi and Chantapacdepong, 2017; Potjagailo, 2017; Gagnon, Bayoumi, Londono, Saborowski and Sapriza, 2017; Rey; 2016; Edward, 2016; Chen et al., 2016; Taylor, 2013; Roger et al., 2013; Neely, 2010), among others.

Quite a number of the aforementioned studies have used the case of US and/or Eurozone to empirically demonstrate that the effects of monetary policy actions in these economies tend to spillover to other countries. For details on the findings of previous studies (see Pham and Phuc, 2019). Even though the majority of the studies mainly focused on the response of real economic activities in the home country to shocks due to spillover of effects of monetary policy shocks from the oversea economies, but Potjaalio (2017) as well as Ammer et al. (2016)are some of the few exceptions to have considered the effect of the spillover on interest rate and other macroeconomic fundamentals. Another major take from the earlier studies is the fact that spillover effects seem exact (similar) across the conventional and unconventional monetary policy tools. However, the extent to which this conclusion holds for developing economies such as Nigeria appears to be missing in the literature.

The dearth of literature in developing economies particularly in the context of unconventional monetary policy can be argued from two perspectives. The first, which is rather general, is that such policies are domestic contingencies, therefore; any spillover is unintended and where it becomes an issue, it is for the policymakers in the source country to address it. The second view which appears specific to developing countries such as Nigeria is that financial markets in most African countries are not fully integrated with global financial markets nor entirely exposed to toxic asset in the crisis hit countries, particularly the United States. This prompted a widely held view that Africa will be spared by the crisis (Bandara, 2010). To this end, there has been scarcity of literature on the spillover effect of monetary policy on African economies.

In view of the above, our study tends to contribute to the literature in threefold. First, we offer new insight on the probable cross-border spillover effects of both conventional and unconventional US monetary policy on financial and macro fundamentals in Nigeria. The fact that the world has become more integrated through financial linkage, findings in this area would offer avenue on how central banks other than those of the developed world can respond to spillover of monetary policy from advanced economies. Second, we considered alternative 
measures of conventional monetary policy to determine the extent to which the spillover effects from such channel of monetary policy is sensitive to the choice of indicators. Third, we captured both the shocks and volatility spillover in our analytical framework simultaneously.

\section{Methodology}

The presence of volatility inherent in most financial series and the inability of the VAR model to capture it justify our preference for volatility-based models as the more appropriate to investigate the probable spill-over effects of US monetary policy on financial and macro fundamentals in Nigeria. More so, the choice of multivariate as against the univariate ARCH or GARCH model is due to the failure of the latter models to capture the causality between the conditional variances of the variables of interest (Salisu and Oloko, 2015). The Vector Conditional Heteroscedasticity (VECH) has been the basis of Multivariate GARCH (MGARCH) models in the literature. For the problems of too many parameters associated with VECH, alternative MGARCH models have been developed to allow for some restrictions, as well as, the possibility of volatility transmission.

Prominent among the alternative MGARCH models are; the Constant Conditional Correlations (CCC)-GARCH developed by Bollerslev (1990), the BEKK-GARCH model by Engle and Kroner (1995), and the Dynamic Conditional Correlations (DCC)-GARCH model by Engle (2002).Revisiting these latter versions of MGARCH models, McAleer (2003) developed a VAR-GARCH model with less computational procedure. This was further modified to account for moving average (MA) terms thus, begetting what is now known as VARMAGARCH model. Both the VAR-GARCH and VARMA-GARCH enable us to capture volatility spillovers in their respective variance equation. But, for the additional feature of shocks spillovers in the mean equation of the latter, the VARMA-GARCH is therefore, employed in this study to investigate both the shocks and volatility spillover effects of U.S monetary policy on macro fundamentals in Nigeria. Notwithstanding, information criteria namely, Schwarz's Bayesian Information Criterion (SBIC) and Akaike information criterion (AIC) were used to arrive at our preference for VARMA-MGARCH as against VAR-MGARCH.

Consequently, we estimate different variants of VAR-GARCH and VARMA-GARCH models, namely: (i) VAR(1,1)-GARCH(1,1); (ii) $\operatorname{VARMA}(1,1)-\operatorname{GARCH}(1,1)$; (iii) $\operatorname{VAR}(2,2)$ GARCH(1,1); (iv) VARMA(2,2)-GARCH(1,1); (V) VAR(3,3)-GARCH(1,1); and (vi) VARMA 
$(3,3)$-GARCH$(1,1)$. Each of these variants of MGARCH models are evaluated with options of CCC, DCC and BEKK. The essence is to ensure that all the possible inherent features of the investigated series are accounted for in the estimation process.

Following Salisu and Oloko (2015), the following is a generic representation of bivariate $\operatorname{VARMA}(p, q)-\operatorname{MGARCH}(1,1)^{5}$ model:

\section{a. The Conditional Mean Equation:}

$$
Z_{t}=\phi+\psi_{1} Z_{t-1}+\psi_{1} Z_{t-2}+\cdots+\psi_{p} Z_{t-p}+\delta_{1} \varepsilon_{t-1}+\delta_{1} \varepsilon_{t-2}+\cdots+\delta_{q} \varepsilon_{t-q}+\varepsilon_{t}, \varepsilon_{t} \sim N\left(0, H_{t}\right)
$$

Re-specifying equation (1) in a more compact form using lag operator will yield the following;

$$
\psi(L) Z_{t}=\phi+\delta(L) \varepsilon_{t} ; \psi(L)=I-\psi_{1} L-\cdots-\psi_{p} L^{p}
$$

and

$$
\begin{aligned}
& \delta(L)=I+\delta_{1} L+\cdots+\delta_{q} L^{q} \\
& \varepsilon_{t}=H_{t}^{1 / 2} v_{t}, v_{t} \sim N(0,1), \varepsilon \sim N\left(0, H_{t}\right)
\end{aligned}
$$

where;

$$
H_{t}=\left[h_{i j t}\right] ; i, j=1,2 ; 1 \Rightarrow \text { MAC and } 2 \Rightarrow U S M P
$$

The MAC in equation (1) denotes the variant measures of macroeconomic fundamentals in Nigeria to include interest rate (INTR), exchange rate (EXR) and inflation (INFL), while $U S M P$ on the other hand represents the different measures for conventional and unconventional monetary policy in U.S. Thus, the $Z_{t}=\left(M A C_{t}, U S M P_{t}\right)^{\prime}$ is a vector which singly captured each of the macro fundamentals as well as the foreign variables in the bivariate specification. The $\phi=\left(\lambda^{M A C}, \lambda^{U S M P}\right)^{\prime}$ is a vector of constant for the macro fundamentals

\footnotetext{
${ }^{5}$ We allow for more than one lag in the mean equation for instance VAR or VARMA, while the variance equation only contains one lag (i.e., GARCH $(1,1)$ ). This, according to Salisu \& Oloko (2015) is because "if the mean model is wrong, it implies that there are more dynamics in the model than included and this can be fixed by reasonably increasing the number of lags in the mean equation. However, in the case of the variance equation (MGARCH), the rejection of MGARCH means that the GARCH part of the model is somehow inadequate". It is very rare in the literature to add lags to MGARCH specification, rather a different version of the MGARCH such as $\mathrm{CCC} / \mathrm{DCC} / \mathrm{BEKK}-\mathrm{MGARCH}$ is often considered.
} 
and U.S monetary policy in the mean equation, respectively. Similarly, $\psi=\left[\begin{array}{ll}\psi_{11} & \psi_{12} \\ \psi_{21} & \psi_{22}\end{array}\right]$ is a $(2 \times 2)$ matrix of coefficients on the lagged terms of the change series, while $\delta=$ $\left[\begin{array}{ll}\phi_{11} & \phi_{12} \\ \phi_{21} & \phi_{22}\end{array}\right]$ is a $(2 \times 2)$ matrix of coefficients on the lagged terms of the residuals where $\varepsilon_{t}=\left(\begin{array}{ll}\varepsilon_{t}^{M A C} & \varepsilon_{t}^{U S M P}\end{array}\right)^{\prime}$ is a vector of disturbance terms for MAC (macro fundamental variables) and USMP (U.S monetary policy variables) in the mean equation, respectively. The

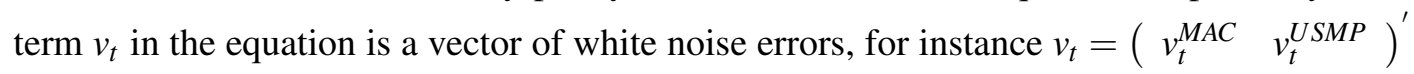
while $H_{t}=\left[h_{i j t}\right]$ is a $(2 \times 2)$ matrix of conditional variances.

\section{b. The Conditional Variance Equation}

Equation (1) is the conditional mean equation following a generalized framework, the associated conditional variance equation on the other hand is as specified in equation (5). However, despite the potential of any of the CCC, DCC and BEKK options to be infused in the VARMA-GARCH set up, the CCC option as earlier mentioned is conventionally imbedded in the set up. Hence, the CCC-VARMA $(p, q)-\operatorname{MGARCH}(1,1)$ is therefore, the starting point for our conditional variance equation and the specification procedures is as follows:

Let $H_{t}^{1 / 2} D_{t}$; then, $\operatorname{var}\left(\varepsilon_{t} / \sum_{t-1}\right)=H_{t}=D_{t} \Gamma D_{t}$;

where $\sum_{t-1}$ is the past information available at time $t-1$ and $\Gamma=E\left(v_{t} v_{t}^{\prime} / \sum_{t-1}\right)=E\left(v_{t} v^{\prime}\right)=$ $\rho_{i j}$ denoting the constant conditional covariance matrix of the unconditional shocks. Since the $H_{t}$ is the conditional covariance matrix, it can be used to accommodate the interdependencies between the macro fundamentals in Nigeria and monetary policy in the U.S. Following McAleer (2003), the $H_{t}$ can then, be expressed as follows:

$$
H_{t}=\Omega+A \varepsilon_{t-1}^{2}+B H_{t-1}
$$

where $H_{t}=\left(h_{t}^{M A C}, h_{t}^{U S M P}\right)^{\prime}$

and consequently, $D_{t}=\operatorname{diag}\left(h_{1}^{1 / 2}, h_{2}^{1 / 2}\right) \varepsilon_{t}^{2}=\left(\varepsilon_{M A C, t}^{2}, \varepsilon_{U S M P, t}^{2}\right)^{\prime}$, and $\Omega, A$, and $B$ are $(2 \times 2)$ matrices of constant, ARCH effects and GARCH effects, respectively.

For the conditional variance with the option of DCC, the representation for the VARMAMGARCH model is as shown below.

$$
\Gamma=\left\{\left(\operatorname{diag}\left(H_{t}\right)^{-1 / 2}\right)\right\} H_{t}\left\{\left(\operatorname{diag}\left(H_{t}\right)^{-1 / 2}\right)\right\}
$$

where $H_{t}$ is a positive definite matrix given as:

$$
H_{t}=\left(1-\pi_{1}-\pi_{2}\right) \bar{H}+\pi_{1} \eta_{t-1} \eta_{t-1}^{\prime}+\pi_{2} H_{t-1}
$$


while $\pi_{1}$ and $\pi_{2}$ denote the dynamic conditional correlations; $\eta_{t}=\left(\varepsilon_{1 t} / \sqrt{h_{1 t}}, \ldots, \varepsilon_{m t} / \sqrt{h_{m t}}\right)^{\prime}$ is the vector of standardized residuals; $H_{t}$ is the conditional covariance matrix that is conditional on the vector of standardized residuals; and $\bar{H}$ is the unconditional variance matrix of $\eta_{t}$. Note that the $\pi_{1}$ and $\pi_{2}$ are non-negative scalar parameters to capture, respectively, the effects of previous shocks and previous dynamic conditional correlations on the current dynamic conditional correlation.

The conditional variance for BEKK option in the representation of VARMA-MGARCH is as given below.

$$
H_{t}=\Omega \Omega+A^{\prime} \varepsilon_{t-1} \varepsilon_{t-1}^{\prime} A+B^{\prime} H_{t-1} B
$$

Where $A$ and $B$ are square matrices while $\Omega$ is a low triangular matrix defined as:

$$
A=\left[\begin{array}{ll}
a_{11} & a_{12} \\
a_{21} & a_{22}
\end{array}\right], B=\left[\begin{array}{ll}
b_{11} & b_{12} \\
b_{21} & b_{22}
\end{array}\right], \Omega=\left[\begin{array}{cc}
\Omega_{11} & 0 \\
\Omega_{21} & a_{22}
\end{array}\right]
$$

Equation (7) can further be broken down into individual conditional variance equations as defined below.

$$
\begin{aligned}
& h_{1 t}=\Omega \Omega_{1}^{\prime}+\alpha_{11} \varepsilon_{1 t-1}^{2}+\alpha_{12} \varepsilon_{2 t-1}^{2}+\beta_{11} h_{1 t-1}+\beta_{12} h_{2 t-1} \\
& h_{2 t}=\Omega \Omega_{2}^{\prime}+\alpha_{21} \varepsilon_{1 t-1}^{2}+\alpha_{22} \varepsilon_{2 t-1}^{2}+\beta_{21} h_{1 t-1}+\beta_{22} h_{2 t-1}
\end{aligned}
$$

The volatility spillover effects appear more evident in equations (8) and (9). For instance, the conditional variance of macro fundamentals (MAC) in equation (9) depends not only on own innovations, but also on shocks due to changes in monetary policy in the U.S. The same explanation holds for the conditional variance of say USMP in equation (9), but this study is mainly concerned about equation (8).

\section{c. The Estimation Technique}

The quasi-maximum likelihood estimator (QMLE) is widely used to estimate parameters in the GARCH based volatility model. The QMLE as given by McAleer (2003) involves maximizing the likelihood function.

$$
L_{n}(\lambda)=\frac{1}{n} \sum_{t=1}^{n} l_{t}(\lambda), l_{t}(\lambda)=\frac{1}{2} \ln \left|D_{t} \Gamma D_{t}\right|-\frac{1}{2} \varepsilon_{t}^{\prime}\left(D_{t} \Gamma D_{t}\right)^{-1} \varepsilon_{t},
$$

where $L_{n}(\lambda)$ takes the form of the Gaussian log-likelihood; $\lambda$ denotes the vector of parameters to be estimated and $D_{t} \Gamma D_{t}=\varepsilon_{t} \varepsilon_{t}^{\prime}=D_{t} \eta_{t} \eta_{t}^{\prime} D_{t}$. Given that $\eta_{t}$ is non-normal, which is a 
prominent feature of most financial series including those under consideration in this paper.

\section{Result Presentation and Discussion}

\subsection{Data Description and Preliminary Analysis}

This study covers two main classes of variables namely, domestic and foreign variables. Starting with the domestic variables, the prime lending rate, Naira/USD exchange rate, and consumer price index are used for proxies for the interest rate (INTR), exchange rate (EXR), and Inflation rate (INFL) respectively, for the financial and macro fundamentals. The foreign variables include the US conventional and unconventional monetary policies. However, while the Fed rate is generally accepted as a viable proxy for the CMP, the measure for UMP is rather ambiguous. For instance, the U.S unconventional monetary policy had three rounds of QE, namely, QE1, QE2 and QE3, respectively. Each of these programmes generally amounted to the Federal Reserve buying Treasury Securities and Mortgage-backed Securities. To this end, the sum of Treasury Securities, Mortgage-backed Securities (MBS) held by the Federal Reserve, as well as the size of the Fed's balance sheet are often considered as proxy(ies) for quantitative easing.

However, since private borrowing, lending, and spending decision presumably depend on (risky) non-treasury rates, reducing their spread over (riskless) treasuries, reduces the interest rates that matter for actual transactions even if riskless rates are unchanged (see Blinder, 2010). It is in this light, among others, that we define the Federal Reserve's unconventional measures, particularly the large-scale purchases of sovereign (e.g. Treasuries) and private (e.g. agency MBS) assets, as two monetary policy "indicators" - (i) the U.S term spread between the 10-year and 3-month treasury yields; and (ii) the U.S corporate spread between the Bank of America Merrill Lynch U.S corporate AAA bond yield and the effective federal funds rate. For easy identification of these measures, we tagged the former as unconventional monetary policy 1 (UMP_1) and the latter as unconventional monetary policy 2 (UMP_2).

Although, all the data are monthly observations but the recent literature on the unconventional monetary policy were mostly spurred by the 2007/2008 GFC. Hence, the sample period was partitioned into full-sample and sub-sample periods. To understand the direction and magnitude of the spillovers effect of conventional monetary policy (CMP) in US on macro fundamentals in Nigeria, a full-sample covering the period between January 1985 and 
December 2018was utilized. With respect to the spillovers effect of the unconventional monetary policy (UMP), a sub-sample period with September 2007, the start date, was carefully determine to purposely coincide with the 2007/2008 GFC periods. On the whole, the foreign data are sourced from the Federal Reserve database; the domestic variables are obtained from the CBN online database. With the exception of UMPs which are readily defined as a differenced series, all the remaining variables namely, CMP, INTR, INFL and EXR are transformed to change series using the following formula: $\hat{y}_{t}=100 * \log \left(y_{\mathrm{t}} / y_{\mathrm{t}-1}\right)$.

Following a standard practice in the literature, we visually inspect as shown in the figures 1 3, possible co-movement between the U.S monetary policy and each of the macroeconomic fundamentals in Nigeria. A cursory look at Figure 1 between January 1985 and December 1991 suggests that there is potential positive co-movement between the US monetary policy and inflation in Nigeria. Since 1992 however, what is evident is potential possible negative co-movement. For the period 2009 and 2015, monetary policy in the U.S seems to be following a stable trend thus suggesting that domestic factors other than foreign interest rates might be responsible for inflation dynamics in Nigeria within the period. The latter period between 2016 and 2018 are further characterized with evidence of possible negative co-movement between the U.S monetary policy and inflation in Nigeria.

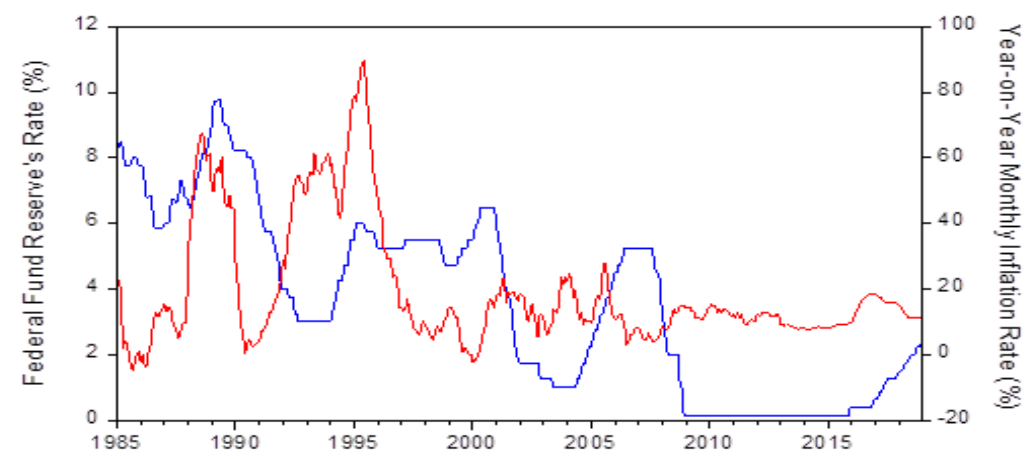

Figure 1: Trends in Nigerian Inflation and monetary policy in US(1985-2018)

$$
\text { - USPR - INFL }
$$

Stemming from the above is mixed evidence of probable positive and negative correlation between the U.S monetary policy and inflation in Nigeria. This is as suggested by the trendy pattern of their possible co-movements. The scenario is, however, a possibility in the case of exchange rate and the U.S monetary policy. A careful inspection of Figure 2 shows that, while monetary policy in the U.S has been characterized with episodes of easing and tight- 
ening, the Naira/USD exchange rate on the other hand has been trending in a direction. Put differently, not minding the monetary policy pronouncement in the U.S, the Naira/USD exchange rate has been predominantly trending in an upward direction (depreciation). Notable exception to this seemingly possible negative co-movement between Naira/USD exchange rate and U.S monetary policy is between 2012 and 2015, where they both seem to be moving at a stable state.

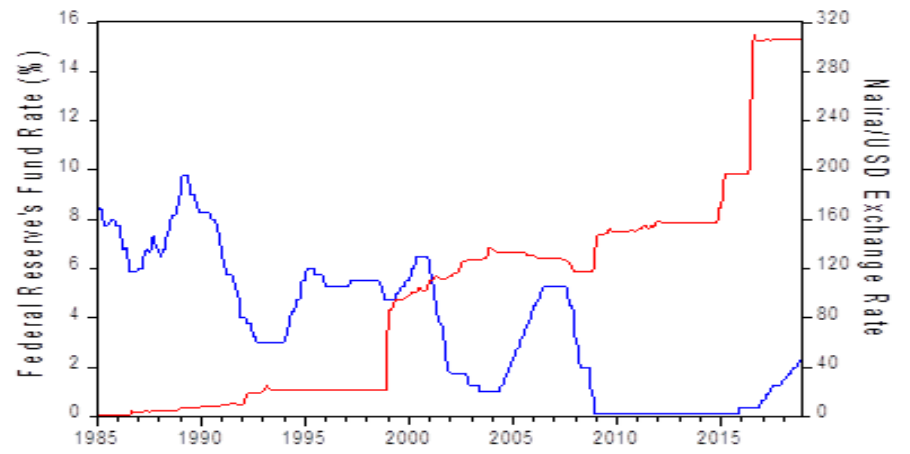

Figure 2: Trends in Naira/USD exchange rate and monetary policy in US (1985-2018) - USPR — Nara/USD

Further depicted in Figure 3 is the trend in domestic interest rate and U.S monetary policy. Except for the period 1987 and 1991 where monetary policies in both economies appear to be moving in the same direction, the movement have been absolute in the opposite direction for the two economies.

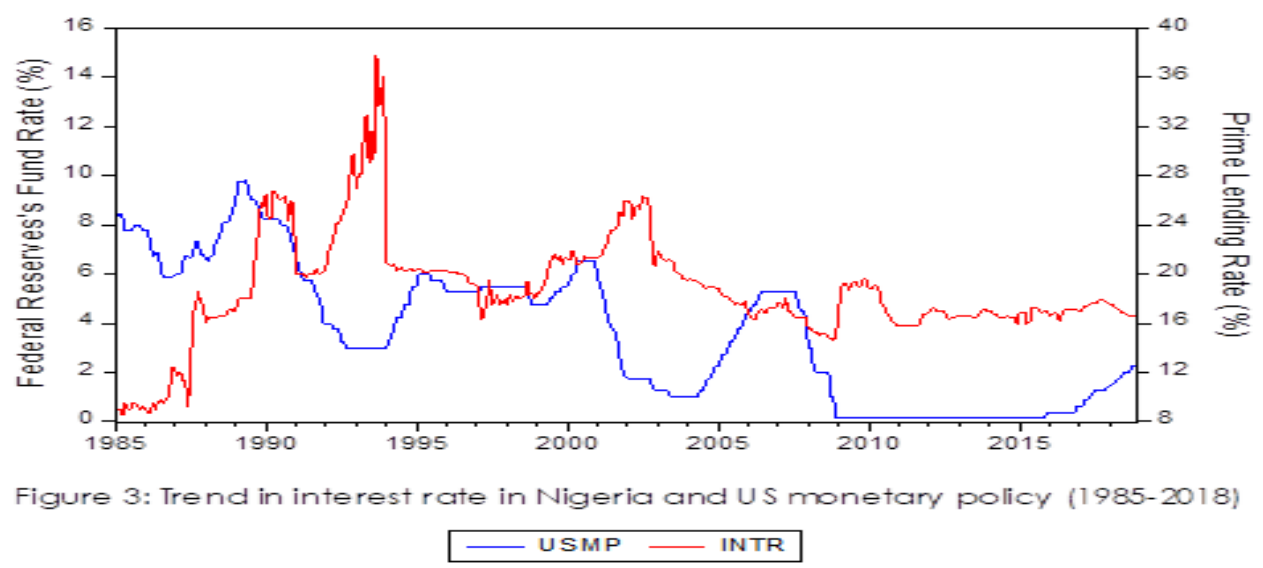

Thus far, our preliminary analysis via graphical illustration has been mainly informal, devoid of any statistical support. We therefore extend our preliminary analysis to include statistical based evidence regarding the inherent statistical features of the variables. The essence is 
to be guided in determining the most appropriate estimation technique among the available alternatives suitable for the estimation of spillover effect of U.S monetary policy to macroeconomic fundamentals in Nigeria.

Starting with full-sample preliminary analysis results in Table 1A, the mean of the summary statistics indicates the average monetary policy rate in the U.S to be 3 per cent. This can be considered as relatively low when compared to average interest rates in Nigeria which is 18 per cent for the period under consideration. Again, as typical of developing economies, average consumer price index, a measure for inflation in Nigeria is as high as 68 index point, while about N99 on average is required in exchange for $\$ 1$. The standard deviation statistic which is 85.77 for the Naira/USD exchange rate and 71.35 for inflation, further points out the uncertain nature of the macroeconomic fundamentals. This evidence of high volatility of macro fundamentals is not surprising, rather it is another conventional barometer for describing developing economies.

Regarding the skewness and kurtosis statistics, we find that virtually all the series are positively skewed, while the result seems to be mixed in the case of kurtosis statistic. For instance, the evidence is platykurtic for all the macro fundamentals, but leptokurtic for CMP. Overall, both the skweness and kurtosis statistics show that the series are non-zero in the case of former and greater than or less than 3 in the case of the later. Confirming these statistics is the Jarque-Bera (JB) test results. Given the statistical significance of the probability $(\mathrm{P})$ values associated with JB test statistic, the test consistently rejects the null hypothesis that the series are normally distributed.

Also, reported in table $1 \mathrm{~A}$ are the results for conditional heteroscedasticity and autocorrelation using ARCH LM test and Ljung-Box test, respectively. The ARCH LM test result indicates the presence of heteroscedasticity except for exchange rate while the evidence in the case of interest rate is mixed across the different lag lengths considered. Results from the Ljung-Box test also indicate the presence of autocorrelation in virtually all the variables in both levels and squared standardized residuals. Finally, we test for the presence of unit root in the series using the Augmented Dickey Fuller (ADF) unit root test. As expected of change (transformed) series, all the variables are reported as stationary.

On the likelihood of the preliminary results been sensitivity to the three rounds of the QE 
episode, we further consider the preliminary tests for a sub-sample period covering September 2007 and December 2018 mainly to understand the statistical features of the unconventional monetary policy variables. A cursory look at Table 1B however, confirmed the robustness of the preliminary results. For instance, we find little or no significance difference in the preliminary results across both the full-sample and sub-sample periods. More importantly, we find the null hypothesis of unit root consistently rejected in all case (i.e. full period \& sub -sample period). With this, we have sufficient condition to favour the conventional approach to modelling spillover effects of monetary policy shocks using Vector Autocorrelation (VAR) model. But for the presence of heteroscedasticity and autocorrelation, which is evident in both the full -sample and sub-sample analyses, it thus become necessary to validate the appropriateness of the VAR model to capture these additional features.

Table 1A: Pre-test analyses result for full-sample (1985-2018)

\begin{tabular}{|c|c|c|c|c|}
\hline Statistics & INTR & EXR & INFL & CMP \\
\hline \multicolumn{5}{|c|}{ Descriptive statistics } \\
\hline Mean & 18.6983 & 99.0119 & 68.1275 & 3.6135 \\
\hline Standard Dev. & 4.3445 & 85.7776 & 71.3557 & 2.7878 \\
\hline Skewness & 0.6778 & 0.7304 & 1.1311 & 0.1979 \\
\hline Kurtosis & 5.5592 & 3.0397 & 3.3690 & 1.8147 \\
\hline Jarque-Bera & $142.5855 * * *$ & $36.3013^{* * *}$ & $89.3160 * * *$ & $26.5456^{* * *}$ \\
\hline \multicolumn{5}{|c|}{ Conditional heteorscedasticity and autocorrelation tests } \\
\hline ARCH LM (2) & $2.1800(0.11)$ & $0.0032(0.99)$ & $3.9432(0.02)$ & $1.8470(0.15)$ \\
\hline ARCH LM (5) & $2.7949(0.01)$ & $0.0058(1.00)$ & $2.8867(0.01)$ & $0.7512(0.58)$ \\
\hline ARCH LM (10) & $1.4620(0.15)$ & $0.0102(1.00)$ & $1.7843(0.06)$ & $0.3764(0.98)$ \\
\hline $\mathrm{LB}(2)$ & $0.4443(0.80)$ & $0.3408(0.84)$ & $144.52(0.00)$ & $27.384(0.00)$ \\
\hline $\mathrm{LB}(5)$ & $11.168(0.04)$ & $1.419(0.92)$ & $183.54(0.00)$ & $31.710(0.04)$ \\
\hline $\mathrm{LB}(10)$ & $28.469(0.00)$ & $1.991(0.99)$ & $211.04(0.00)$ & $45.619(0.00)$ \\
\hline $\mathrm{LB} 2(2)$ & $4.7077(0.09)$ & $0.006(0.99)$ & $8.7185(0.01)$ & $3.745(0.58)$ \\
\hline LB2(5) & $15.382(0.00)$ & $0.030(0.10)$ & $17.587(0.00)$ & $3.790(0.58)$ \\
\hline LB2(10) & $16.524(0.08)$ & $0.108(0.10)$ & $21.830(0.01)$ & $3.914(0.95)$ \\
\hline Observations & 408 & 408 & 408 & 408 \\
\hline \multicolumn{5}{|c|}{ Stationarity test using ADF unit root test } \\
\hline Level & $-20.8096^{b * * *}$ & $-19.9723^{b * * *}$ & $-8.7532^{b * * *}$ & $-10.6996^{b * * *}$ \\
\hline First Difference & N/A & N/A & N/A & N/A \\
\hline \multicolumn{5}{|c|}{$\begin{array}{l}\text { Note: The ARCH LM tests refer to the Engle (1982) test for conditional heteroscedasticity while } \\
\text { the LB and LB }{ }^{2} \text { imply the Ljung-Box tests for autocorrelations involving the standardized residuals } \\
\text { in levels and squared standardized residuals, respectively. The unit root test is performed using } \\
\text { Augmented Dickey-Fuller (ADF) approach. The N/A implies not applicable while ***, ** and } \\
* \text { indicates significance at } 1 \%, 5 \% \text { and } 10 \% \text {, respectively. The sub-scripts }{ }^{b} \text { implies the model is } \\
\text { with constant and trend. }\end{array}$} \\
\hline
\end{tabular}


Spillover effect of United States Monetary Policy on Nigeria's Financial and Macro Fundamentals.

Ekeocha and Udeaja

Table 1B: Pre-test analyses result for unconventional monetary policy sample (2007- 2018)

\begin{tabular}{|c|c|c|c|c|c|}
\hline Statistics & INTR & EXR & INFL & UMP_1 & UMP_2 \\
\hline \multicolumn{6}{|c|}{ Descriptive statistics } \\
\hline Mean & 16.8940 & 189.2049 & 154.0711 & 1.6296 & 2.4498 \\
\hline Standard Dev. & 1.0452 & 65.3262 & 55.2847 & 0.7079 & 0.9902 \\
\hline Skewness & 0.6217 & 1.0347 & 0.5754 & -0.1367 & 1.5768 \\
\hline Kurtosis & 3.5704 & 2.4651 & 2.2989 & 2.1144 & 6.8404 \\
\hline Jarque-Bera & $10.6035 * * *$ & $25.8867 * * *$ & $10.2899 * * *$ & $4.8672 *$ & $139.9318 * * *$ \\
\hline \multicolumn{6}{|c|}{ Conditional heteorscedasticity and autocorrelation tests } \\
\hline ARCH LM (2) & $11.130(0.00)$ & $12.151(0.00)$ & $1.4447(0.23)$ & $659.57(0.00)$ & $84.001(0.00)$ \\
\hline ARCH LM (5) & $4.4902(0.00)$ & $4.7877(0.00)$ & $0.6764(0.64)$ & $279.94(0.00)$ & $32.703(0.00)$ \\
\hline ARCH LM (10) & $2.4185(0.01)$ & $2.2214(0.02)$ & $0.7247(0.69)$ & $128.92(0.00)$ & $23.130(0.00)$ \\
\hline $\mathrm{LB}(2)$ & $8.9678(0.01)$ & $34.836(0.00)$ & $19.562(0.00)$ & $234.46(0.00)$ & $219.38(0.00)$ \\
\hline $\mathrm{LB}(5)$ & $15.123(0.01)$ & $35.385(0.00)$ & $21.218(0.00)$ & $491.39(0.00)$ & $427.41(0.00)$ \\
\hline $\mathrm{LB}(10)$ & $16.381(0.08)$ & $37.160(0.00)$ & $34.178(0.00)$ & $775.41(0.00)$ & $532.12(0.00)$ \\
\hline $\mathrm{LB}^{2}(2)$ & $20.525(0.00)$ & $21.396(0.00)$ & $1.4673(0.48)$ & $200.19(0.00)$ & $130.49(0.00)$ \\
\hline $\operatorname{LB}^{2}(5)$ & $20.621(0.00)$ & $18.813(0.00)$ & $2.0092(0.84)$ & $338.98(0.00)$ & $226.97(0.00)$ \\
\hline $\mathrm{LB}^{2}(10)$ & $21.396(0.01)$ & $19.376(0.01)$ & $14.048(0.17)$ & $387.09(0.00)$ & 233.43 \\
\hline Observations & 136 & 136 & 136 & 136 & 136 \\
\hline \multicolumn{6}{|c|}{ Stationarity test using ADF unit root test } \\
\hline Level & $-8.8790^{a} * * *$ & $-7.8267^{b * * *}$ & $-8.4222^{a * * *}$ & $-8.7812^{b * * *}$ & - \\
\hline & & & & & $3.3267^{b * *}$ \\
\hline First Difference & N/A & N/A & N/A & N/A & N/A \\
\hline
\end{tabular}

Note: The ARCH LM tests refer to the Engle (1982) test for conditional heteroscedasticity while the $L B$ and $L B^{2}$ imply the Ljung-Box tests for autocorrelations involving the standardized residuals in levels and squared standardized residuals, respectively. The unit root test is performed using Augmented Dickey-Fuller (ADF) approach. The N/A implies not applicable while ***, ** and * indicates significance at $1 \%, 5 \%$ and $10 \%$, respectively. The sub-scripts ${ }^{a} \&^{b}$ implies model with constant and model with constant and trend, respectively.

Presented in Table 2A is the post-estimation results obtained from the diagnostic tests performed on the various VAR models estimated using full-sample period, while same was considered for the sub-sample period and the results are documented in Table 2B. The essence is to determine the appropriateness of the VAR to capture the conditional heteroscedasticity feature of the series in addition to its traditional usefulness for modelling spill-over effects of monetary policy shocks. For the sake of robustness and consistency, we considered several alternative VAR models. The ARCH and LM tests consistently failed to reject the null hypothesis of heteroscedasticity and autocorrelation in the VAR models. The fact that the evidence holds consistently for both the full-sample and sub-sample scenarios, thus motivate out preference for a multivariate GARCH model with the potential to capture spill-over effects, conditional volatility (heteroscedasticity) and autocorrelation features of the variables 
under consideration.

Table 2A: Post estimation results on the estimated VAR models using full-sample(19852018)

\begin{tabular}{|c|c|c|c|}
\hline INTR-CMP nexus & $\begin{array}{l}\text { ARCH-LM } \\
\text { (without cross term) }\end{array}$ & $\begin{array}{l}\text { ARCH-LM } \\
\text { (with cross term) }\end{array}$ & $\begin{array}{l}\text { Serial Correlation } \\
(\mathrm{LM}) \text { test }\end{array}$ \\
\hline $\operatorname{VAR}(2)$ & $91.8658 * * *(0.0000)$ & $305.9726 * * *(0.0000)$ & $1.1592(0.3213)$ \\
\hline $\operatorname{VAR}(5)$ & $150.8537 * * *(0.0000)$ & $620.2091 * * *(0.0000)$ & $1.1709(0.2725)$ \\
\hline $\operatorname{VAR}(10)$ & $172.9353(0.0000)$ & $968.3000 * * *(0.0000)$ & $0.6301(0.9646)$ \\
\hline \multicolumn{4}{|l|}{ EXR-CMP nexus } \\
\hline $\operatorname{VAR}(2)$ & $199.6473 * * *(0.0000)$ & $358.0382 * * *(0.0000)$ & $0.4241(0.9069)$ \\
\hline $\operatorname{VAR}(5)$ & $200.2524 * * *(0.0000)$ & $509.9711 * * *(0.0000)$ & $0.4315(0.9863)$ \\
\hline $\operatorname{VAR}(10)$ & $270.7011 * * *(0.0000)$ & $895.5575 * * *(0.0000)$ & $0.3465(1.0000)$ \\
\hline \multicolumn{4}{|l|}{ INFL -CMP nexus } \\
\hline $\operatorname{VAR}(2)$ & $47.4459 * * *(0.0030)$ & $68.4144 * * *(0.0062)$ & $4.6364 * * *(0.0000)$ \\
\hline $\operatorname{VAR}(5)$ & $109.2290 * * *(0.0001)$ & $365.1798 * * *(0.0000)$ & $1.1837(0.2608)$ \\
\hline $\operatorname{VAR}(10)$ & $190.2283 * * *(0.0000)$ & $1019.320 * * *(0.0000)$ & $2.8167 * * *(0.0000)$ \\
\hline
\end{tabular}

Note: The figures in parentheses are the probability values associated with the F-statistic and Rao F-statistics associated with the ARCH-LM and serial correlation LM tests, respectively. These tests were performed on estimates obtained from the three alternatives VAR specification considered. 
Spillover effect of United States Monetary Policy on Nigeria's

Financial and Macro Fundamentals.

Ekeocha and Udeaja

Table 2B: Post estimation results on the estimated VAR models using sub-sample period (2007-2018)

\begin{tabular}{|c|c|c|c|}
\hline INTR-UMP_1 nexus & $\begin{array}{l}\text { ARCH-LM } \\
\text { (without cross term) }\end{array}$ & $\begin{array}{l}\text { ARCH-LM } \\
\text { (with cross term) }\end{array}$ & $\begin{array}{l}\text { Serial Correlation } \\
\text { (LM) test }\end{array}$ \\
\hline VAR(2) & $32.1060(0.1244)$ & $76.9432 * * *(0.0000)$ & $4.1036 * * *(0.0001)$ \\
\hline $\operatorname{VAR}(5)$ & $103.7891 * * *(0.0004)$ & $432.0485 * * *(0.0000)$ & $1.9813 * * *(0.0065)$ \\
\hline $\operatorname{VAR}(10)$ & $158.2229 * *(0.0111)$ & $960.9745 * * *(0.0000)$ & $1.1058(0.3043)$ \\
\hline \multicolumn{4}{|l|}{ INTR -UMP_2 nexus } \\
\hline VAR-X(2) & $166.7826 * * *(0.0000)$ & $166.7826 * * *(0.0000)$ & $2.4531 * *(0.0126)$ \\
\hline VAR-X(5) & $161.3097 * * *(0.0000)$ & $540.3422 * * *(0.0000)$ & $2.1040 * * *(0.0033)$ \\
\hline VAR-X(10) & $253.4321 * * *(0.0000)$ & $1070.556 * * *(0.0000)$ & $0.8570(0.7213)$ \\
\hline \multicolumn{4}{|l|}{ EXR -UMP_1 nexus } \\
\hline VAR(2) & $27.1084(0.2994)$ & $59.7960 * *(0.0367)$ & $2.4491 * *(0.0127)$ \\
\hline $\operatorname{VAR}(5)$ & $66.3467(0.2675)$ & $227.1362 * *(0.0572)$ & $1.3500(0.1397)$ \\
\hline $\operatorname{VAR}(10)$ & $91.2734(0.9763)$ & $823.0136 * * *(0.0003)$ & $0.8879(0.6695)$ \\
\hline \multicolumn{4}{|l|}{ EXR -UMP_2 nexus } \\
\hline VAR-X(2) & $83.2032 * * *(0.0000)$ & $98.1634 * * *(0.0000)$ & $1.4922(0.1560)$ \\
\hline VAR-X(5) & $103.2153 * * *(0.0004)$ & $285.4205 * * *(0.0000)$ & $0.9916(0.4699)$ \\
\hline VAR-X(10) & $144.5140 *(0.0632)$ & $787.1255 * * *(0.0059)$ & $0.5191(0.9942)$ \\
\hline \multicolumn{4}{|l|}{ INFL -UMP1 nexus } \\
\hline $\operatorname{VAR}(2)$ & $18.5329(0.7764)$ & $55.0673 *(0.0852)$ & $3.3815 * * *(0.0008)$ \\
\hline $\operatorname{VAR}(5)$ & $47.0976(0.8874)$ & $240.3973 * *(0.0148)$ & $1.4984 *(0.0748)$ \\
\hline $\operatorname{VAR}(10)$ & $93.0690(0.9675)$ & $697.4657(0.4136)$ & $1.8256 * * *(0.0017)$ \\
\hline \multicolumn{4}{|l|}{ INFL -UMP2 nexus } \\
\hline VAR-X(2) & $82.9057 * * *(0.0000)$ & $92.1792 * * *(0.0000)$ & $1.2179(0.2852)$ \\
\hline VAR-X(5) & $110.5985 * * *(0.0001)$ & $316.3754 * * *(0.0000)$ & $1.2435(0.2107)$ \\
\hline VAR-X(10) & $187.8896 * * *(0.0001)$ & $974.0228 * * *(0.0000)$ & $1.9208 * * *(0.0007)$ \\
\hline
\end{tabular}

\subsection{Empirical Analyses}

Presented in Tables 3A \& 3B are the summary of the different features of the two variants of MGARCH models under consideration. Under each specification, the competing MGARCH models are ranked to determine the model with the best fit via SBIC and AIC, such that the discussion of results mainly based on the best-fit model whose selection is made systematically using these criteria. Note that the comprehensive report of the model selection results is in the appendix. Starting with the full-sample scenario, the ranking in table $3 \mathrm{~A}$ is a summary of the reports on model selection. In the detail report, models that do not achieve convergence of several iterations are not considered for ranking, because non convergence implies that the model is not successfully solved. For the solved model, the smaller the AIC or SBIC values the better the fit. However, where there is conflict between the judgments of AIC and SBIC, 
the SBIC is considered since it gives higher penalty to too many parameters in the model (see Salisu and Oloko, 2015).

Table 3A:Summary of model feature for full-sample (1985-2018)

\begin{tabular}{|c|c|c|c|}
\hline Model & $\begin{array}{l}\text { Return spillovers } \\
\text { captured? }\end{array}$ & $\begin{array}{l}\text { Volatility spillovers } \\
\text { captured? }\end{array}$ & $\begin{array}{l}\text { Shock spillovers cap- } \\
\text { tured? }\end{array}$ \\
\hline VAR-MGARCH & Yes & Yes & No \\
\hline VARMA-MGARCH & Yes & Yes & Yes \\
\hline \multicolumn{4}{|c|}{ Selected Best Fit MGARCH Model for Interest rate -US monetary policy nexus } \\
\hline & Convergence Status & \multicolumn{2}{|l|}{ Selection Criteria } \\
\hline INTR-CMP & & SBC & Rank \\
\hline BEKK: & Achieved & 5.429 & 2nd \\
\hline \multicolumn{4}{|c|}{$\operatorname{VAR}(3)-M G A R C H(1,1)$} \\
\hline BEKK: & Achieved & 5.285 & $1 \mathrm{st}$ \\
\hline \multicolumn{4}{|c|}{$\operatorname{VARMA}(3)-M G A R C H(1,1)$} \\
\hline \multicolumn{4}{|c|}{ Selected Best Fit MGARCH Model for Exchange rate -US monetary policy nexus } \\
\hline & Convergence Status & \multicolumn{2}{|l|}{ Selection Criteria } \\
\hline EXR-CMP & & SBC & Rank \\
\hline BEKK: & Achieved & 3.309 & 2nd \\
\hline \multicolumn{4}{|c|}{$\operatorname{VAR}(2)-M G A R C H(1,1)$} \\
\hline BEKK: & Achieved & 3.054 & $1 \mathrm{st}$ \\
\hline \multicolumn{4}{|c|}{$\operatorname{VARMA}(3)-M G A R C H(1,1)$} \\
\hline \multicolumn{4}{|c|}{ Selected Best Fit MGARCH Model for Inflation -US monetary policy nexus } \\
\hline & Convergence Status & \multicolumn{2}{|l|}{ Selection Criteria } \\
\hline INFL -CMP & & SBC & Rank \\
\hline BEKK: & Achieved & 6.635 & 2nd \\
\hline \multicolumn{4}{|c|}{$\operatorname{VAR}(1)-M G A R C H(1,1)$} \\
\hline BEKK: & Achieved & 6.766 & $1 \mathrm{st}$ \\
\hline \multicolumn{4}{|c|}{ VARMA(3)-MGARCH $(1,1)$} \\
\hline
\end{tabular}

Regarding the variant features of MGARCH models, the VAR-MGARCH model allows us to capture both returns and volatility spillovers, while the VARMA-MGARCH on the other hand further accounts for shocks spillover in the mean equation. Recall, that each of these models were evaluated with the options of CCC, DCC and BEKK. But a look at table 3A reveals the BEKK option as dominant to the other two options. This, however, may be due to the need to compute conditional correlation coefficient by both CCC and DCC MGARCH options which is not required by the BEKK option. Essentially, we find the BEKK-VARMA (3)-MGARCH(1,1) as the best fit model for analysing the spilover effects of conventional monetary policy (CMP) to macro fundamentals in Nigeria. 
Even when sample period mainly covered the unconventional monetary policy episodes starting from September 2007, a look at table 3B yet reveal BEKK-VARMA(3)-MGARCH(1,1) as the best fit model for analysing the spilover effects of unconventional monetary policy (CMP) to macro fundamentals in Nigeria. The only exception in this regard is when the nexus is INTR-UNMP_2, where BEKK:VAR(3)-MGARCH(1,1) appears to be the best fit model.

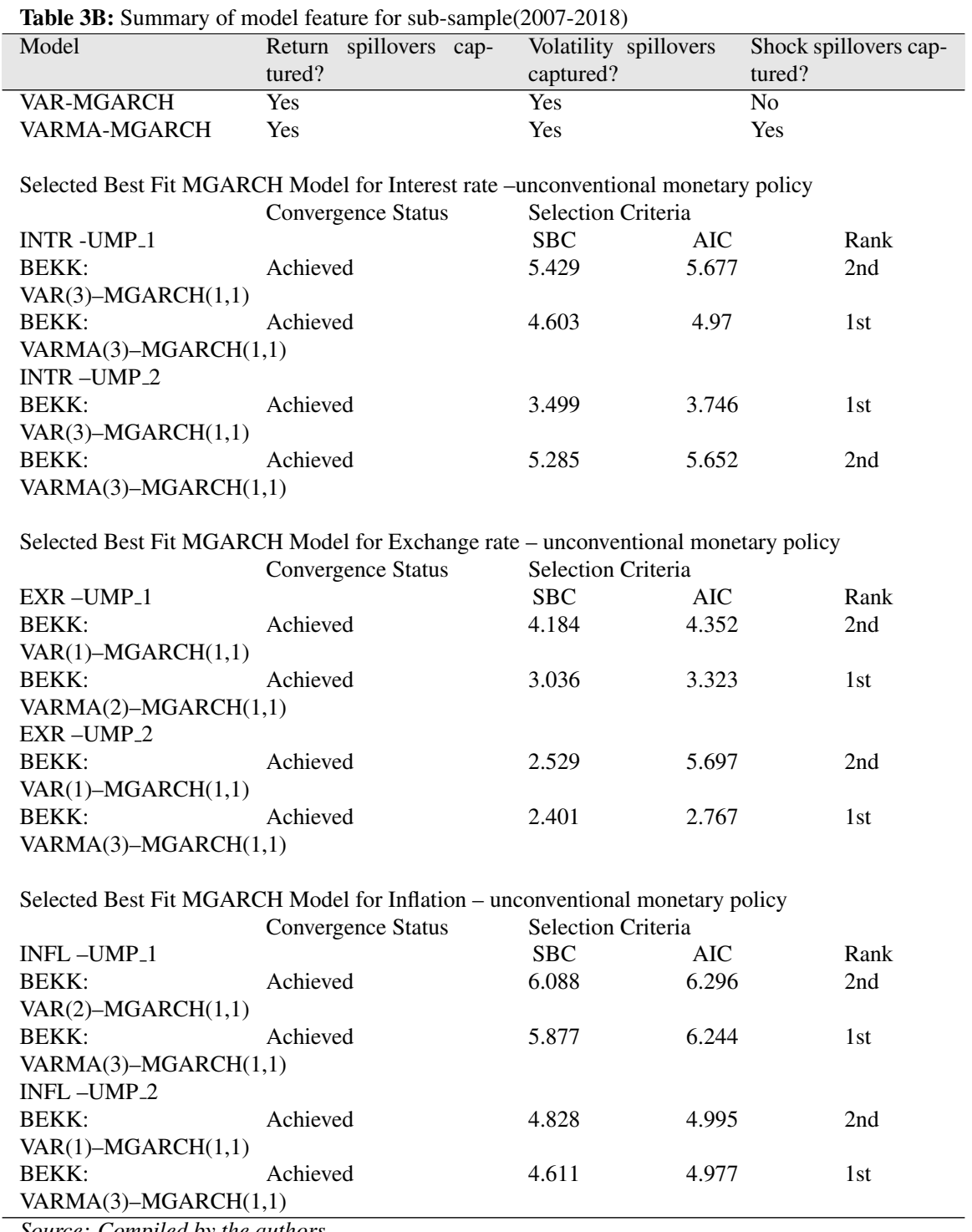




\subsubsection{Spillover Effects of Conventional Monetary Policy (CMP) in US on Macro Fundamentals in Nigeria}

Starting with the mean equation, the empirical estimates in Table 4 show that there no evidence of significant spillovers effect of CMP on interest rate in Nigeria. This which finds support in Pham and Phuc (2019) is an indication that interest rate in Nigeria is driven mainly by own innovation as captured by the coefficient on the lagged term $\left(\psi_{11}\right)$ of interest rate. We however, observed evidence of positive and significant shock spillover effects of CMP on interest rate $\left(\phi_{12}\right)$. What this portends, is that for a positive monetary policy shocks in US, the $\mathrm{CBN}$ is likely to favour an expansionary monetary policy to counter the effects of the spillover on the domestic interest rate. We also find evidence of short-term volatility spillover effects of CMP on interest rate in Nigeria $\left(\alpha_{12}\right)$, thus suggesting that shocks to CMP in US are likely to cause higher volatility in the Nigerian interest rate. This though seems to be consistent with Claus et al., (2016) and Hnatkovska et al., (2016) findings, we however, find little or no evidence of long run volatility spillover effects of CMP on interest rate in Nigeria.

Similar to the interest rate mean equation, the estimates from the mean equation on CMP exchange rate nexus, indicates no spillover effects from MPC to exchange rate in Nigeria. However, for the shock and variance equations, we find evidence of negative and significant spillover effect from CMP to exchange. This by implication suggests that a contractionary monetary policy in US is likely to prompt the appreciation of Naira relative to USD. With respect to the CMP -inflation nexus, the estimates from both the mean and variance equations appear to be suggesting that inflation in Nigeria is mainly driven by own innovations. 
Spillover effect of United States Monetary Policy on Nigeria's

Financial and Macro Fundamentals.

Ekeocha and Udeaja

Table 4: Empirical estimates of spillover effects of conventional monetary policy (CMP) using full sample (1985-2018)

\begin{tabular}{|c|c|c|c|}
\hline Parameter & Interest rate (INTR) & Exchange rate (EXR) & Inflation (INFL) \\
\hline \multicolumn{4}{|c|}{ Mean equation } \\
\hline$\lambda_{10}$ & $-0.0005(0.0012)$ & $0.0134 * *(0.0054)$ & $0.0060 * * *(0.0008)$ \\
\hline$\psi_{11}$ & $0.1979 * * *(0.0568)$ & $0.1390(0.1503)$ & $0.4889 * * *(0.0724)$ \\
\hline$\psi_{12}$ & $-0.0094(0.0065)$ & $-0.0456(0.0480)$ & $-0.0069(0.0043)$ \\
\hline$\phi_{11}$ & $-0.0089 * * *(0.0000)$ & $0.0081(0.0000)$ & $-0.0350 * * *(0.0000)$ \\
\hline$\phi_{12}$ & $0.1369 * * *(0.0000)$ & $-0.0784 * * *(0.0000)$ & $0.3273 * * *(0.0000)$ \\
\hline$\lambda_{20}$ & $0.0035(0.0033)$ & $-0.0001(0.0043)$ & $0.0009(0.0052)$ \\
\hline$\psi_{22}$ & $0.5766 * * *(0.0886)$ & $0.2711(0.1067)$ & $0.3019 * * *(0.0807)$ \\
\hline$\psi_{21}$ & $0.0100(0.0704)$ & $0.0119(0.0398)$ & $0.0653(0.1984)$ \\
\hline$\phi_{22}$ & $-0.1457 * * *(0.000)$ & $-0.1368 * * *(0.0000)$ & $-0.0158 * * *(0.0000)$ \\
\hline$\phi_{21}$ & $0.0058 * * *(0.000)$ & $-0.1801(0.0000)$ & $-0.0719 * * *(0.0000)$ \\
\hline \multicolumn{4}{|c|}{ Variance equation } \\
\hline$\Omega_{11}$ & $-0.0087 * * *(0.0014)$ & $0.0987 * * *(0.0107)$ & $0.0098 * * *(0.0012)$ \\
\hline$\Omega_{21}$ & $-0.0093(0.0091)$ & $0.0043(0.0077)$ & $-0.0030(0.0063)$ \\
\hline$\Omega_{22}$ & $0.08067 * * *(0.0045)$ & $0.0443 * * *(0.0072)$ & $0.0459 * * *(0.0040)$ \\
\hline$\alpha_{11}$ & $0.7580 * * *(0.0562)$ & $0.1631(0.1427)$ & $1.2203 * * *(0.1533)$ \\
\hline$\alpha_{12}$ & $0.0024 * * *(0.0931)$ & $-0.0242(0.0532)$ & $-0.1489(0.3619)$ \\
\hline$\alpha_{21}$ & $0.0319 * * *(0.0072)$ & $-0.0157(0.0707)$ & $-0.0077(0.0063)$ \\
\hline$\alpha_{22}$ & $0.8018 * * *(0.0882)$ & $0.5046 * * *(0.0515)$ & $0.5113 * * *(0.0529)$ \\
\hline$\beta_{11}$ & $0.7562 * * *(0.0295)$ & $0.1247(0.8090)$ & $0.3967 * * *(0.0657)$ \\
\hline$\beta_{12}$ & $0.0110(0.0549)$ & $0.0462(0.3101)$ & $0.1314(0.1793)$ \\
\hline$\beta_{21}$ & $-0.0338 * * *(0.0108)$ & $-0.0289(0.0461)$ & $0.0018(0.0083)$ \\
\hline$\beta_{22}$ & $0.3023 * * *(0.1152)$ & $0.8191 * * *(0.0262)$ & $0.8132 * * *(0.0262)$ \\
\hline \multicolumn{4}{|c|}{ Diagnostic test results } \\
\hline Ljung-Box $Q(2)$ & $4.2062(0.12)$ & $12.2627(0.35)$ & $2.6621(0.05)$ \\
\hline Ljung-Box $Q(5)$ & $0.655(0.72)$ & $10.7718(0.31)$ & $4.5155(0.22)$ \\
\hline McLeod-Li(2) & $10.1432(0.06)$ & $10.2023(0.96)$ & $4.4412(0.71)$ \\
\hline McLeod-Li(5) & $1.0873(0.50)$ & $11.0213(0.56)$ & $2.8123(0.10)$ \\
\hline
\end{tabular}

Note: Values in parenthesis are the standard error for the coefficient but p-value for the diagnostic test statistics, while *,** and $* * *$ represent level of significance at $1 \%, 5 \%$ and $10 \%$ respectively.

\subsubsection{Spillover Effects of Unconventional Monetary Policy (UMP) in US on Macro Fundamentals in Nigeria}

Presented in Table 5 are the empirical estimates on the probable spillover effects of unconventional monetary policy in US on interest rate, exchange rate and inflation in Nigeria. Unlike our earlier findings, where we find no evidence of significant spillover effects of CMP on any of these fundamentals in the mean equation, both the exchange rate and inflation appear to be vulnerable to unconventional monetary policy in U.S. This evident is particularly more pronounced when the measure for UMP is corporate spread between the Bank of America Merrill Lynch U.S corporate AAA bond yield and the effective federal funds rate (i.e. UMP_2). We also find that each of the fundamentals under consideration not only responded 
to shocks due to own innovations, but also to shocks due to spillovers effects of UMP irrespective of whether the measure for UMP is UMP_1 and/or UMP_2.

Quite an interesting further observation in table 5 is the fact that the sign on the spillover effects of the mean equation is positive for exchange and negative for inflation. This is an indication that the UMP has the potential to be beneficial to both the exchange rate and inflation in Nigeria. On the one hand, we find the likelihood of the UMP prompting exchange rate appreciations in Nigeria. On the hand, is the probable of the UMP causing declining inflation rate in Nigeria. This finding did fit well with the huge import dependent peculiarity of Nigeria economy on goods from US. Thus, not only will efforts to curb the problem of imported inflation be realized by monetary policy initiated domestically, policy action in the source country can as well be of benefit.

Again, when compared to the volatility spillover effects of CPM, a look at the empirical estimates from the variance equation in table 5 , show that the volatility spillover effects of the UMP hold virtually for all the macro fundamentals but vary for UMP_1 and UMP_2. For instance, we find short run volatility spillover effects of UMP on interest but mainly when the UMP is measured as the U.S term spread between the 10-year and 3-month treasury yields for instance UMP_1. Whereas the significance of the volatility spillover effects of the UMP on exchange rate not only hold mainly in the short run situation but also when the UMP is measure as corporate spread between the Bank of America Merrill Lynch U.S corporate AAA bond yield and the effective federal funds rate. Intuitively, the fact that the sign on UMP_1 coefficient is negative in the interest rate equation while the sign on UMP_2 is positive in the exchange rate equation further reaffirm our earlier submission that the spillover effects of the unconventional monetary policy in U.S. maybe beneficial to macro fundamentals in Nigeria.

However, not only are the volatility spillover effects of UMP_1 and UMP_2 hold for inflation in Nigeria, the significance of the spillover seems consistent both in the short and long run situations, particularly when the measure for unconventional monetary policy is UMP_1. Overall, we find the volatility spillover effects of the unconventional monetary policy as capable of inducing a short term easing monetary policy response. There is also the likelihood of the volatility spillover effects leading to the appreciation of Naira relative to USD at least in the short run, while the potential of the effects of the volatility spillover leading to declining inflation rate seems to be viable both in the short and long run. 
Spillover effect of United States Monetary Policy on Nigeria's Financial and Macro Fundamentals.

Ekeocha and Udeaja

Table 5: Empirical estimates of spillover effects of unconventional monetary policy (UCMP) using sub-sample (2007-2018)

\begin{tabular}{|c|c|c|c|}
\hline Parameter & $\begin{array}{l}\text { UMP_1 } \\
\text { Interest rate (INTR) }\end{array}$ & Exchange rate (EXR) & Inflation (INFL) \\
\hline \multicolumn{4}{|c|}{ Mean equation } \\
\hline$\lambda_{10}$ & $-0.0011(0.0033)$ & $0.0143 * * *(0.0013)$ & $0.0019 * *(0.0008)$ \\
\hline$\psi_{11}$ & $0.1703 *(0.0989)$ & $-0.2409 * * *(0.0429)$ & $0.3941 * * *(0.1040)$ \\
\hline$\psi_{12}$ & $0.0173(0.0116)$ & $0.0125 * * *(0.0015)$ & $0.0014(0.0018)$ \\
\hline$\phi_{11}$ & $0.0182 * * *(0.0000)$ & $-0.0838 * * *(0.0000)$ & $0.0281 * * *(0.0000)$ \\
\hline \multirow[t]{2}{*}{$\phi_{12}$} & - & $-0.1053 * * *(0.0000)$ & $0.0084 * * *(0.0000)$ \\
\hline & $0.0168 * * *(0.0000)$ & & \\
\hline$\lambda_{20}$ & $0.0268(0.0327)$ & $-0.0311(0.0276)$ & $0.0425(0.0411)$ \\
\hline$\psi_{22}$ & $1.4986 * * *(0.0736)$ & $1.2941 * * *(0.0560)$ & $1.3370 * * *(0.0863)$ \\
\hline$\psi_{21}$ & $-0.6829(0.6704)$ & $0.1206(0.5947)$ & $0.7272(2.4436)$ \\
\hline \multirow[t]{2}{*}{$\phi_{22}$} & - & $-0.2219 * * *(0.0000)$ & $0.1577 * * *(0.0000)$ \\
\hline & $0.0094 * * *(0.0000)$ & & \\
\hline$\phi_{21}$ & $0.0448 * * *(0.0000)$ & $0.0080 * * *(0.0000)$ & $0.0047 * * *(0.0000)$ \\
\hline \multicolumn{4}{|c|}{ Variance equation } \\
\hline$\Omega_{11}$ & $-0.0026(0.0020)$ & $-0.0003(0.0006)$ & $0.0003(0.0003)$ \\
\hline$\Omega_{21}$ & $0.1040 * * *(0.0134)$ & $-0.0416(0.0265)$ & $0.0679 * * *(0.0124)$ \\
\hline$\Omega_{22}$ & $-0.0233(0.0360)$ & $0.0209(0.0516)$ & $-0.0000(0.0956))$ \\
\hline$\alpha_{11}$ & $0.4433 * * *(0.1101)$ & $2.5254 * * *(0.1995)$ & $0.6766 * * *(0.1187)$ \\
\hline \multirow[t]{2}{*}{$\alpha_{12}$} & - & $-0.3534(1.0242)$ & $-1.6843 * * *(0.7319)$ \\
\hline & $1.9704 * * *(0.1135)$ & & \\
\hline$\alpha_{21}$ & $0.1015 * * *(0.0242)$ & $-0.0064(0.0042)$ & $-0.0033(0.0021)$ \\
\hline$\alpha_{22}$ & $0.1267(0.0911)$ & $0.0677(0.0681)$ & $0.2972 * *(0.1576)$ \\
\hline$\beta_{11}$ & $0.2881(0.2506)$ & $0.0019(0.0078)$ & $-0.7607 * * *(0.0430)$ \\
\hline$\beta_{12}$ & $0.8209(1.2394)$ & $-0.1239(0.3983)$ & $-2.1249 * * *(1.4008)$ \\
\hline$\beta_{21}$ & $0.0740 * * *(0.0139)$ & $0.0143 * * *(0.0039)$ & $0.0063 * * *(0.0022)$ \\
\hline$\beta_{22}$ & $0.3730 * * *(1051)$ & $-0.9095 * * *(0.0179)$ & $-0.6359 * * *(0.1162)$ \\
\hline \multicolumn{4}{|c|}{ Diagnostic test results } \\
\hline Ljung-Box $Q(2)$ & $11.4617(0.40)$ & $12.2627(0.35)$ & $1.560(0.45)$ \\
\hline Ljung-Box $Q(5)$ & $11.6718(0.32)$ & $10.7718(0.31)$ & $2.563(0.76)$ \\
\hline McLeod-Li(2) & $4.1120(0.86)$ & $10.2023(0.96)$ & $0.526(0.76)$ \\
\hline McLeod-Li(5) & $13.3002(0.60)$ & $11.0213(0.56)$ & $2.202(0.02)$ \\
\hline
\end{tabular}

Note: UMP_l is measured as the U.S term spread between the 10-year and 3-month treasury yields while UMP_2 is measured as the U.S corporate spread between the Bank of America Merrill Lynch U.S corporate AAA bond yield and the effective federal funds rate. The values in parenthesis are the standard error for the coefficient but p-value for the diagnostic test statistics, while *,** and *** represent level of significance at $1 \%$, $5 \%$ and $10 \%$ respectively. 
Table 5 contd.: Empirical estimates of spillover effects of unconventional monetary policy (UCMP) using sub-sample (2007-2018)

\begin{tabular}{|c|c|c|c|}
\hline Parameter & $\begin{array}{l}\text { UMP_2 } \\
\text { Interest rate (INTR) }\end{array}$ & Exchange rate (EXR) & Inflation (INFL) \\
\hline \multicolumn{4}{|c|}{ Mean equation } \\
\hline$\lambda_{10}$ & $-0.0045(0.0055)$ & $-0.0009 * * *(0.0001)$ & $0.0006(0.0007)$ \\
\hline$\psi_{11}$ & $0.1762 *(0.0958)$ & $0.2885 * * *(0.0081)$ & $0.4707 * * *(0.0809)$ \\
\hline$\psi_{12}$ & $0.0099(0.0071)$ & $0.0057 * * *(0.0001)$ & $-0.0032 * * *(0.0006)$ \\
\hline$\phi_{11}$ & - & $0.0143 * * *(0.0000)$ & $0.0127 * * *(0.0000)$ \\
\hline & $0.2470 * * *(0.0000)$ & & \\
\hline$\phi_{12}$ & $0.2064 * * *(0.0000)$ & $0.0813 * * *(0.0000)$ & $0.0160 * * *(0.0000)$ \\
\hline$\lambda_{20}$ & $0.0927(0.0600)$ & $0.0827 * * *(0.0114)$ & $0.2635 * * *(0.0617)$ \\
\hline$\psi_{22}$ & $1.0821 * * *(0.0853)$ & $1.0753 * * *(0.0090)$ & $1.0639 * * *(0.0813)$ \\
\hline$\psi_{21}$ & $0.2802(0.7573)$ & $-0.6225 * * *(0.2230)$ & $-4.8354 * *(2.1957)$ \\
\hline$\phi_{22}$ & $0.0079(0.0000)$ & $-0.0410 * * *(0.0000)$ & $0.0764 * * *(0.0000)$ \\
\hline$\phi_{21}$ & $0.1047 * * *(0.0000)$ & $-0.0453 * * *(0.0000)$ & $0.0103 * * *(0.0000)$ \\
\hline \multicolumn{4}{|c|}{ Variance equation } \\
\hline$\Omega_{11}$ & $0.0097 * * *(0.0016)$ & $0.0001 * * *(0.0000)$ & $0.0007 * *(0.0003)$ \\
\hline$\Omega_{21}$ & $0.0092(0.0150)$ & $-0.0296 * * *(0.0043)$ & $0.0032(0.0410)$ \\
\hline$\Omega_{22}$ & $-0.0285(0.0214)$ & $0.0012(0.0080)$ & $-0.1130 * * *(0.0137)$ \\
\hline$\alpha_{11}$ & $0.8182 * * *(0.1438)$ & $2.9587 * * *(0.1234)$ & $0.9066 * * *(0.1163)$ \\
\hline$\alpha_{12}$ & $-0.2968(1.0844)$ & $0.7867 * *(0.3912)$ & $-1.9041 * * *(0.7083)$ \\
\hline$\alpha_{21}$ & $0.0299 *(0.0164)$ & $-0.0794 * * *(0.0036)$ & $0.0010(0.0011)$ \\
\hline$\alpha_{22}$ & $-0.0402(0.0893)$ & $-0.0052(0.0310)$ & $0.9148 * * *(0.1092)$ \\
\hline$\beta_{11}$ & $0.3347 *(0.1845)$ & $0.0007(0.0006)$ & $0.7226 * * *(0.0452)$ \\
\hline$\beta_{12}$ & $0.7943(1.2213)$ & $-0.1979(0.1405)$ & $2.7144(1.9563)$ \\
\hline$\beta_{21}$ & $-0.0002(0.0029)$ & $-0.0034 * * *(0.0005)$ & $0.0016 * *(0.0008)$ \\
\hline$\beta_{22}$ & $0.9538 * * *(0.0066)$ & $0.9619 * * *(0.0048)$ & $0.2908 * * *(0.0822)$ \\
\hline \multicolumn{4}{|c|}{ Diagnostic test results } \\
\hline Ljung-Box $Q(2)$ & $1.1707(0.90)$ & $0.1107(0.90)$ & $4.382(0.11)$ \\
\hline Ljung-Box $Q(5)$ & $3.2801(0.10)$ & $0.2121(0.10)$ & $9.935(? ?)$ \\
\hline McLeod-Li(2) & $3.0441(0.66)$ & $11.33441(0.88)$ & $1.801(0.40)$ \\
\hline McLeod-Li(5) & $1.3412(0.61)$ & $12.4122(0.71)$ & $4.900(0.24)$ \\
\hline
\end{tabular}

Note: UMP_l is measured as the U.S term spread between the 10-year and 3-month treasury yields while UMP_2 is measured as the U.S corporate spread between the Bank of America Merrill Lynch U.S corporate AAA bond yield and the effective federal funds rate. The values in parenthesis are the standard error for the coefficient but p-value for the diagnostic test statistics, while *, ** and *** represent level of significance at $1 \%$, $5 \%$ and $10 \%$ respectively.

\subsubsection{Computation of the Persistence of the Spillover Effects}

Using the conditional variance model in equation (6), the short run persistence of the spillover effects or ARCH effect of shocks to inflation or exchange rate can be represented as $\sum_{l=1}^{r} \alpha_{i l}$, while $\sum_{j=1}^{r} \alpha_{i j}+\sum_{j=1}^{s} \beta_{i j}$ captures long run persistence (see Chang et al., 2013). Since $\sum_{l=1}^{s} \beta_{i l}$ in our specified variance equation denotes GARCH effect, we can henceforth explore a simplified representation in line with our model specification such that, the long run persistence 
of shocks to each of the macroeconomic fundamentals can be represented as $\alpha_{11}+\beta_{11}$ and $\alpha_{22}+\beta_{22}$ for the monetary policy variable(s). Hypothetically, the closer the value to one (1), the higher the degree of persistence and where the value is equal to one then it can be referred as perfect persistence.

Table 6a: Shocks persistence results for interest rate-monetary policy nexus

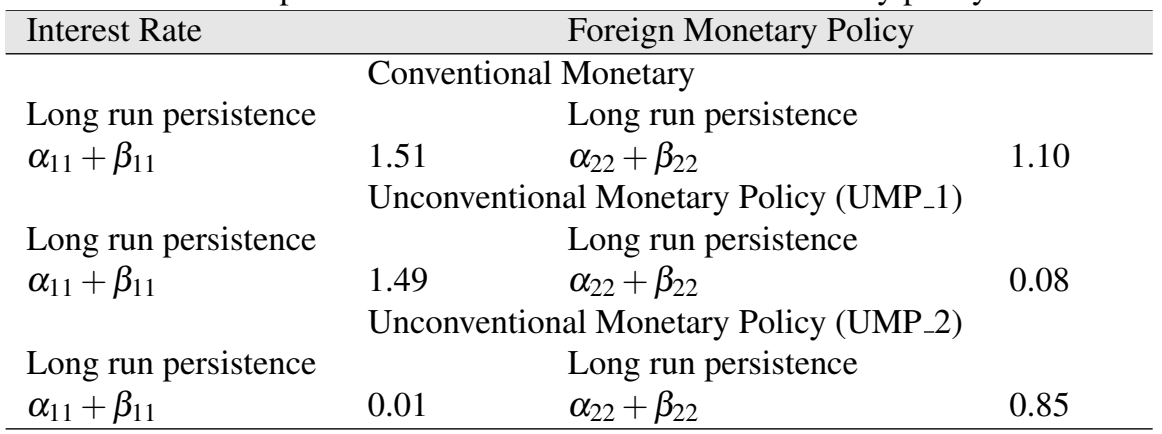

Table 6b: Shocks persistence results for exchange rate-monetary policy nexus

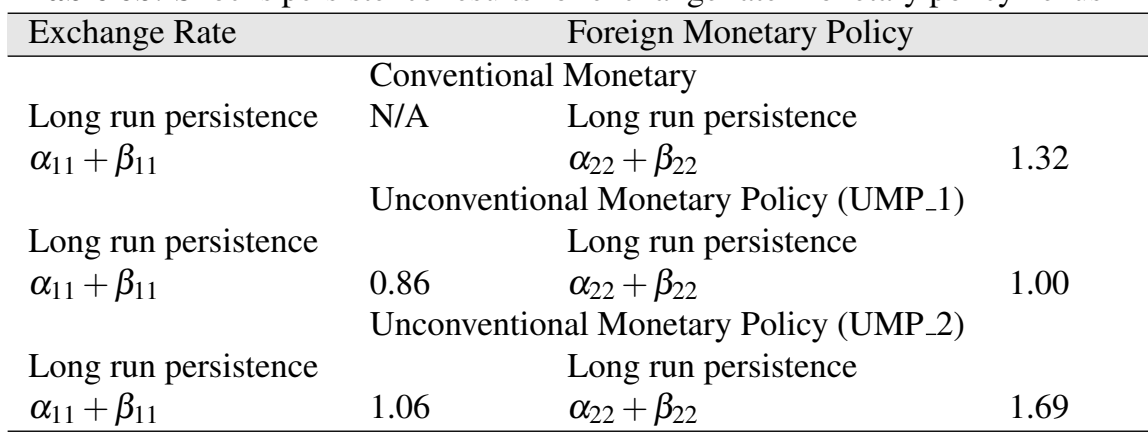

Note: the term N/A implies not available is applicable where the coefficients for the ARCH and GARCH terms are found not significant.

A cursory look at Table 6a shows that a shock to interest rate is not likely to die out overtime. This is particularly evident for the model that includes the conventional monetary policy or when the quantitative easing as a proxy for the unconventional monetary policy is measured via the U.S term spread between the 10-year and 3-month Treasury yields. However, when the measure for the unconventional monetary policy is corporate spread between the Bank of America Merrill Lynch U.S corporate AAA bond yield and the effective federal funds rate, the magnitude of the long run persistence of shocks to interest rate is $(0.01)$. This in particular is an indication that the degree of persistence of shocks to interest rate is likely to vary for CMP and UMP. 
Table 6c: Shocks persistence results for inflation-monetary policy nexus

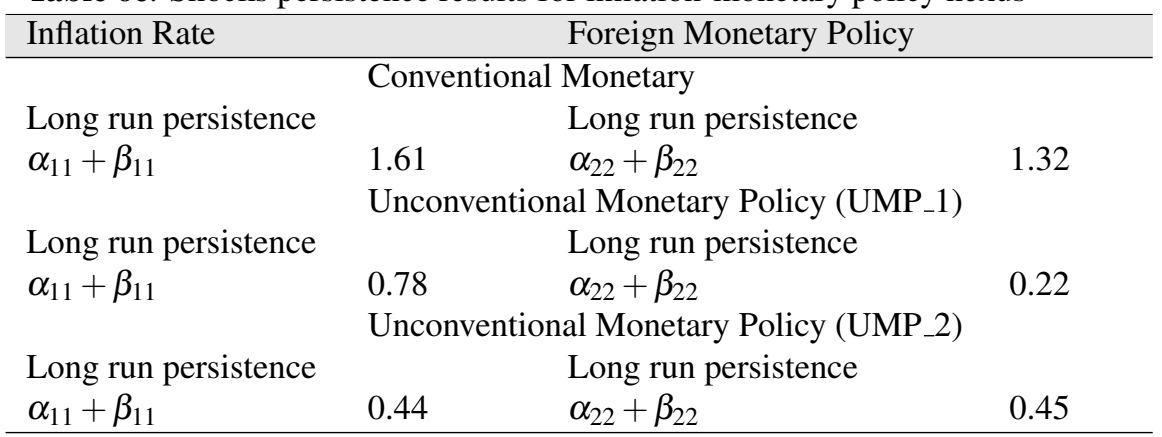

For the Naira/USD exchange rate in Table $6 b$, the term N/A suggests that the coefficients associated with parameters of own shocks and own conditional variance are found not to be significant, respectively. Beyond this, the persistence results at 0.86 and 1.06 are indications that shocks to the Naira/USD exchange rate are permanent across the two measures of quantitative easing under consideration. The exchange rate appears to experience higher long run shocks persistence when volatility due to quantitative easing are captured in the variance equation irrespective of the choice of measure for the unconventional monetary policy.

In the case of inflation in Table $6 \mathrm{c}$, the degree of the persistence of the shocks at 1.68 points to the fact that shocks to inflation is not likely to die out even in the long run, particularly when volatility due to conventional monetary policy is included in the variance equation. However, the evidence is rather mixed for the variance equation where volatility captured include those attributed to unconventional monetary policy, depending on whether the quantitative easing is measured via 'term spread' or 'corporate spread'. For instance, we find evidence of higher long run shocks persistence when 'term spread' proxy for unconventional monetary policy, yet the shocks are likely to be transitory when volatility due to conventional monetary policy is measured via 'corporate spread'.

\section{Conclusion and Policy Recommendations}

Using the case of Nigeria and the US as domestic and foreign economy, respectively, we investigate whether monetary policy activities in one country, particularly, the US, will spillover to financial and macro fundamentals in the other economy, Nigeria. Having carefully undergo rigorous but evidence-based procedures, taken into consideration the probable inherent features of the time series under consideration, we arrived at BEKK-VARMA-MGARCH with the CCC option as our preferred and the best fit model for the analyses of the spillover effects. 
Our main findings are as follows:

We observed that interest rate in Nigeria is likely to be driven by own innovations and shocks within, given our findings of no evidence of significant spillover effects of monetary policy in US to interest rate. This is in line with some of the findings from the previous studies (see Pham and Phuc, 2019),but it is mainly with respect to the mean equation of the estimated model as far as this present study is concerned. However, our empirical finding from the variance equation suggests that there is a volatility spillover effect of monetary policy in US to interest rates in Nigeria at least in the short run situation.

In addition to our observation of varying spillover effects of CMP and UMP on exchange rate, we also find the significance of the effects to vary for CMP and UMP in the short and long-run. Overall, we find that spillover effects of monetary policy activities in US have the potential to strengthen Naira against dollar both for the conventional and unconventional monetary policy actions.

Equally on a positive note is our observation of the spillover effects of both the conventional and unconventional monetary policy actions in US leading to declining inflation rate in Nigeria. Replicating this possibility is our finding of negative and significant volatility spillover effects of the CMP and UMP on inflation in Nigeria. This is an, indication that efforts to curb problem of imported inflation can be realized both domestically as well as via the spillover effects of monetary policy actions in the U.S.A.

In view of the above empirical findings, it becomes imperative to be cautious of the actions of monetary policy authorities in one country and the likely implications of such action on another economy. Put differently, the study recommends that the monetary policy technical committee (MPTC) of the Central Bank of Nigeria (CBN) should continue to monitor not only the developments at the domestic level but also at the international sphere. That is, when preparing monetary policy document for the Monetary Policy Committee (MPC) meetings, the MPTC should take cognizance of the monetary policy activities of Nigeria's major trading partners particularly, the United States (U.S). 


\section{References}

Ammer, J., Pooter, M.D., Erceg, C. \& Kamin, S. (2016). International Spillovers of Monetary Policy. IFDP Notes.

Apostolou, A. \& Beirne, J. (2019). Volatility spillovers of unconventional monetary policy to emerging market economies. Economic Modelling, doi: https://doi.org/10.1016/j.econmod.2018.10.006.

Bandara, A. (2010). The Impact of Global Financial and Economic Crisis on Africa: Transmission Channels and Policy Implications. Being a Conference Paper Presented at the International Conference on "Rethinking African Economic Policy in Light of the Global Economic and Financial Crisis" held in Nairobi, Kenya on 6-8 December 2009. Bank for International Settlements (2016): 86th Annual Report, June.

Bartkiewicz, P. (2018). The impact of quantitative easing on emerging Markets-literature review. Financial Internet Quarterly, e-Finanse, 14(4), 67-76.

Bayoumi, T. \& Andrew, S. (2009). Foreign Entanglements: Estimating the Source and Size of Spillovers across Industrial Countries. IMF/Staff Papers, No. 56 (2).

Beaton, K. \& Brigitte, D. (2011). Financial Spillovers across Countries: The Case of Canada and the United States. Bank of Canada Discussion Paper. www.bank-banquecanada.ca

Blinder, A. (2010). Quantitative easing: entrance and exit strategies. Federal Reserve Bank of St. Louis Review, November/December.

Bollerslev, T. (1990).Modelling the coherence in short-run nominal exchange rates: Multivariate Generalized ARCH Approach. Review of Economics and Statistics, 72, 498505.

Chang C., McAleer M. \& Tansuchat, R. (2013). Conditional correlations and volatility spillovers between crude oil and stock index returns. North American Journal of Economics and Finance, 25, 116-138.

Chen, Q., Filardo, A., He, D. \& Zhu, F. (2016).Financial crisis, US unconventional monetary policy and international spillovers. Journal of International Money and Finance, $67,62-81$.

Chen, Q., Filardo, A., He, D. \& Zhu F. (2014a). Global Impact of US Monetary Policy at the Zero Lower Bound. Manuscript, Bank for International Settlements.

Chen, J., Mancini-Griffoli, T. \& Sahay, R. (2014b). Spillovers from United States Monetary Policy on Emerging Markets: Different This Time? International Monetary Fund Working Paper WP/14/240. 
Chen, Q., Filardo, A., He, D. \& Zhu F. (2015). Financial Crisis, US Unconventional Monetary Policy and International Spillovers. Bank for International Settlements, ISSN 1682-7678.

Chinn, M.D. (2013). Global Spillovers and Domestic Monetary Policy: The Effects of Conventional and Unconventional Measures. Paper prepared for the 12th BIS annual conference "Navigating the great recession: what role for monetary policy?" 20-21 June, Luzern, Switzerland.

Claus, E., Claus, I. \& Krippner, L. (2016). Monetary policy spillovers across the Pacific when interest rates are at the zero lower bound. Discussion Paper Series, DP216/08, Reserve Bank of New Zealand.

Colombo, V. (2013). Economic policy uncertainty in the US: Does it matter for the Euro area? Economics Letters, 121, 39-42.

Edwards, S. (2016). The Federal Reserve and monetary policy in Latin America: is there policy spillover? Presented at the Hoover Institution Monetary Policy Conference, California, 5-6.

https://www.hoover.org/sites/default/files/research/docs/rulesforinternationalmonetary stability-ch1.pdf

Ehrmann, M., Fratzscher, M. \& Rigobon, R. (2011). Stocks, bonds, money markets and exchange rates: measuring international financial transmission. Journal of Applied Econometrics, 26(6), 948-974.

Ehrmann, M. \& Fratzscher, M. (2004). Equal Size, Equal Role? Interdependence between the Euro Area and the United States. ECB Working Paper, 342, European Central Bank (ECB).

Engle, R.F. (2002). Theoretical and Empirical Properties of Dynamic Conditional Correlation Multivariate GARCH. NBER Working Paper.

Engle, R.F. \& Kroner, K.F. (1995). Multivariate simultaneous generalized ARCH. Econometric Theory, 11, 122-150.

Engle, R. (1982). Autoregressive Conditional Heteroscedasticity with estimates of the variance of the U.K. inflation. Econometrica, 50, 987-1008.

Fleming, J.M. (1962). Domestic financial policies under fixed and under floating exchange rates. International Monetary Fund Staff Papers, 9 (3), pp. 369-80.

Gagnon, J.E., Bayoumi, T., Londono, J.M., Saborowski, C. \& Sapriza, H. (2017). Direct and spillover effects of unconventional monetary and exchange rate policies. IMF Working Paper WP/ 17/56,

Available at: https://www.imf.org/en/Publications/WP/Issues/2017/03/13/DirectandSpillover-Effects-of-Unconventional-Monetary-and-Exchange-Rate-Policies-44743 
Hajek, J. \& Horvath, R. (2015). The Spillover Effect of Euro Area on Central and Southeastern European Economies: A Global VAR Approach. Springer Publisher New York 2015.

Hnatkovska, V., Lahiri, A. \& Vegh, C.A. (2016).The exchange rate response to monetary policy innovations. American Economic Journal: Macroeconomics, 8, 137-81.

Janus, J. (2015). The Transmission Mechanism of Unconventional Monetary Policy. Institute of Economic Research Working Papers, No. 57.

Joyce, M., Miles, D., Scott, A. \& Vayanos, D. (2012).Quantitative easing and unconventional monetary policy - an introduction. The Economic Journal, 122, pp. 271-288.

Landau, J.P. (2013). Global Liquidity: Public and Private. Unpublished manuscript.

Iacoviello, M. \& Navarro, G. (2018).Foreign effects of higher U.S. interest rate. Journal of International Money and Finance, Article in Press.www.elsevier.com/locate/jimf

Kose, M.A., Lakatos, C., Ohnsorge, F., \& Stocker, M. (2017). The Global Role of the U.S. economy: Linkages, policies and spillovers. Working Paper, 1706, Koç UniversityTÜSİAD Economic Research Forum (ERF), Istanbul.http://hdl.handle.net/10419/166746

Kuroda, H. (2016). The practice \& theory of unconventional monetary policy. Contemporary issues in macroeconomics, J.E. Stiglitz et al. (eds.), 7-14

McAleer, M. (2003). Automated inference and learning in modelling financial volatility. Econometric Theory, 21, 232-261.

Mundell, R.A. (1963). Capital mobility and stabilization policy under fixed and flexible exchange rates. Canadian Journal of Economic and Political Science, 29(3), 475-85.

Neely, C., 2010. The large-scale asset purchases had large international effects. Federal Reserve Bank of St. Louis Working Paper, no 2010-018, July.

Pham, T.T. \& Phuc, N.T. (2019). Monetary policy responses of Asian countries to spillovers from US monetary policy. Asian Pacific Economic Literature, doi: 10.1111/apel.12254

Potjagailo, G. (2017). Spillover effects from Euro area monetary policy across Europe: a factor augmented VAR approach. Journal of International Money and Finance, 72, $127-47$.

Punzi, M.T. \& Chantapacdepong, P. (2017). Spillover effects of unconventional monetary policy in Asia and the Pacific. ADBI Working Paper Series, Available at:https://www.adb.org/sites/default/files/publication/220146/adbiwp630.pd

Rey, H. (2016). International channels of transmission of monetary policy and the Mundelliantrilemma. IMF Economic Review, 64(1), 6-35. 
Rogers, J, Scotti, C. \& Wright, J. (2013).Evaluating Asset-Market Effects of Unconventional Monetary Policy: A Cross-Country Comparison. International Finance Discussion Papers No 1101, Board of Governors of the Federal Reserve System.

Salisu, A.A. \& Oloko, T. (2015).Modelling oil price-US stock nexus: A VARMA-BEKKAGARCH approach. Energy Economics, Elsevier, 50(C), 1-12.

Shuairu, T. \& Shigeyuki, H. (2016). Time-varying price shock transmission and volatility spillover in foreign exchange, bond, equity, and commodity markets: Evidence from the United States. North American Journal of Economics and Finance, 38, 163-171.

Taylor, J.B. (2001). The role of the exchange rate in monetary-policy rules. American Economic Review, 91(2), pp. 263-7.

Taylor, J.B. (2007). Globalization and monetary policy: missions impossible. in J. Gali and M.J. Gertler (eds.), International Dimensions of Monetary Policy, 1st ed., University of Chicago Press, Chicago: 609-24.

Taylor, J. (2013). International monetary coordination and the great deviation. Journal of Policy Modeling, 35(3), pp. 463-72. 


\section{Appendix}

Table A1: Model Selection Criteria for VAR-MGARCH models on U.S conventional monetary policy and macro fundamentals in Nigeria using full sample

\begin{tabular}{|c|c|c|c|c|}
\hline \multirow[t]{2}{*}{ Model for INTR-CMP } & \multirow[t]{2}{*}{ Convergence Status } & \multicolumn{2}{|c|}{ Selection Criteria } & \multirow[t]{2}{*}{ Rank } \\
\hline & & $S B C$ & $A I C$ & \\
\hline BEKK: VAR(1)-MGARCH(1,1) & Achieved & 5.570 & 5.738 & $3^{r d}$ \\
\hline BEKK: VAR(2)-MGARCH(1,1) & Achieved & 5.515 & 5.723 & $2^{\text {nd }}$ \\
\hline BEKK: VAR(3)-MGARCH(1,1) & Achieved & 5.429 & 5.677 & $1^{s t}$ \\
\hline CC: VAR(1)-MGARCH $(1,1)$ & Not Achieved & 5.583 & 5.731 & Not applicable \\
\hline CC: VAR(2)-MGARCH(1,1) & Not Achieved & 5.537 & 5.725 & Not applicable \\
\hline CC: VAR(3)-MGARCH(1,1) & Not Achieved & 5.487 & 5.715 & Not applicable \\
\hline DCC: VAR(1)-MGARCH $(1,1)$ & Not Achieved & 5.528 & 5.586 & Not applicable \\
\hline DCC: VAR(2)-MGARCH(1,1) & Not Achieved & 5.547 & 5.544 & Not applicable \\
\hline DCC: VAR(3)-MGARCH(1,1) & Not Achieved & - & - & Not applicable \\
\hline \multirow[t]{2}{*}{ Model for EXR-CMP } & \multirow[t]{2}{*}{ Convergence Status } & \multicolumn{2}{|c|}{ Selection Criteria } & Rank \\
\hline & & $S B C$ & $A I C$ & \\
\hline BEKK: VAR(1)-MGARCH(1,1) & Achieved & 3.368 & 3.536 & $2^{\text {nd }}$ \\
\hline BEKK: VAR(2)-MGARCH(1,1) & Achieved & 3.309 & 3.315 & $1^{s t}$ \\
\hline BEKK: VAR(3)-MGARCH( $(1,1)$ & Achieved & 5.071 & 5.319 & $3^{r d}$ \\
\hline CC: VAR(1)-MGARCH(1,1) & Not Achieved & 3.544 & 3.702 & Not applicable \\
\hline CC: VAR(2)-MGARCH(1,1) & Not Achieved & 3.531 & 3.719 & Not applicable \\
\hline CC: VAR(3)-MGARCH(1,1) & Not Achieved & 3.425 & 3.652 & Not applicable \\
\hline DCC: VAR(1)-MGARCH(1,1) & Not Achieved & - & - & Not applicable \\
\hline DCC: VAR(2)-MGARCH(1,1) & Not Achieved & - & - & Not applicable \\
\hline DCC: VAR(3)-MGARCH $(1,1)$ & Not Achieved & - & - & Not applicable \\
\hline \multirow{2}{*}{ Model for INFL-CMP } & \multirow[t]{2}{*}{ Convergence Status } & \multicolumn{2}{|c|}{ Selection Criteria } & Rank \\
\hline & & $S B C$ & $A I C$ & \\
\hline BEKK: VAR(1)-MGARCH(1,1) & Achieved & 6.635 & 6.803 & $1^{s t}$ \\
\hline BEKK: VAR(2)-MGARCH(1,1) & Achieved & 6.645 & 6.852 & $2^{\text {nd }}$ \\
\hline BEKK: VAR(3)-MGARCH(1,1) & Achieved & 6.578 & 6.825 & $3^{r d}$ \\
\hline CC: VAR(1)-MGARCH(1,1) & Not Achieved & 6.747 & 6.895 & Not applicable \\
\hline CC: VAR(2)-MGARCH(1,1) & Not Achieved & 6.699 & 6.887 & Not applicable \\
\hline CC: VAR(3)-MGARCH(1,1) & Not Achieved & 6.700 & 6.928 & Not applicable \\
\hline DCC: VAR(1)-MGARCH( $(1,1)$ & Not Achieved & - & - & Not applicable \\
\hline DCC: VAR(2)-MGARCH(1,1) & Not Achieved & - & - & Not applicable \\
\hline DCC: VAR(3)-MGARCH(1,1) & Not Achieved & - & - & Not applicable \\
\hline
\end{tabular}


Spillover effect of United States Monetary Policy on Nigeria's

Financial and Macro Fundamentals.

Ekeocha and Udeaja

Table A2: Model Selection Criteria for VAR-MGARCH models on U.S unconventional monetary policy and macro fundamentals in Nigeria using sub-sample

\begin{tabular}{|c|c|c|c|c|}
\hline \multirow[t]{2}{*}{ Model for INTR-UMP1 } & \multirow[t]{2}{*}{ Convergence Status } & \multicolumn{2}{|c|}{ Selection Criteria } & \multirow[t]{2}{*}{ Rank } \\
\hline & & $S B C$ & $A I C$ & \\
\hline BEKK: VAR(1)-MGARCH(1,1) & Achieved & 4.917 & 4.985 & $3^{r d}$ \\
\hline BEKK: VAR(2)-MGARCH(1,1) & Achieved & 4.823 & 5.031 & $2^{\text {nd }}$ \\
\hline BEKK: VAR(3)-MGARCH $(1,1)$ & Achieved & 4.804 & 5.052 & $1^{s t}$ \\
\hline CC: VAR(1)-MGARCH(1,1) & Not Achieved & 4.655 & 4.803 & Not applicable \\
\hline CC: $\operatorname{VAR}(2)-M G A R C H(1,1)$ & Not Achieved & 4.869 & 5.057 & Not applicable \\
\hline CC: $\operatorname{VAR}(3)-M G A R C H(1,1)$ & Not Achieved & 4.825 & 5.052 & Not applicable \\
\hline DCC: $\operatorname{VAR}(1)-M G A R C H(1,1)$ & Not Achieved & - & - & Not applicable \\
\hline DCC: $\operatorname{VAR}(2)-M G A R C H(1,1)$ & Not Achieved & - & - & Not applicable \\
\hline DCC: $\operatorname{VAR}(3)-M G A R C H(1,1)$ & Not Achieved & - & - & Not applicable \\
\hline \multicolumn{5}{|l|}{ Model for INTR-UMP2 } \\
\hline BEKK: VAR(1)-MGARCH(1,1) & Achieved & 3.519 & 3.687 & $3^{r d}$ \\
\hline BEKK: VAR(2)-MGARCH(1,1) & Achieved & 3.517 & 3.724 & $2^{\text {nd }}$ \\
\hline BEKK: VAR(3)-MGARCH(1,1) & Achieved & 3.499 & 3.746 & $1^{s t}$ \\
\hline CC: VAR(1)-MGARCH(1,1) & Achieved & 3.563 & 3.711 & $5^{\text {th }}$ \\
\hline CC: $\operatorname{VAR}(2)-M G A R C H(1,1)$ & Achieved & 3.573 & 3.761 & $6^{\text {th }}$ \\
\hline CC: VAR(3)-MGARCH(1,1) & Not Achieved & 3.557 & 3.785 & $4^{\text {th }}$ \\
\hline DCC: VAR(1)-MGARCH(1,1) & Not Achieved & - & - & Not applicable \\
\hline DCC: $\operatorname{VAR}(2)-M G A R C H(1,1)$ & Not Achieved & - & - & Not applicable \\
\hline DCC: VAR(3)-MGARCH(1,1) & Not Achieved & - & - & Not applicable \\
\hline \multicolumn{5}{|l|}{ Model for EXR-UMP1 } \\
\hline BEKK: VAR(1)-MGARCH(1,1) & Achieved & 4.184 & 4.352 & $1^{s t}$ \\
\hline BEKK: VAR(2)-MGARCH(1,1) & Not Achieved & 4.371 & 4.578 & Not applicable \\
\hline BEKK: VAR(3)-MGARCH(1,1) & Not Achieved & 4.475 & 4.723 & Not applicable \\
\hline CC: VAR(1)-MGARCH(1,1) & Not Achieved & 2.756 & 2.904 & Not applicable \\
\hline CC: VAR(2)-MGARCH( $(1,1)$ & Not Achieved & 2.624 & 2.812 & Not applicable \\
\hline CC: VAR(3)-MGARCH(1,1) & Not Achieved & 3.336 & 3.564 & Not applicable \\
\hline DCC: VAR(1)-MGARCH(1,1) & Not Achieved & - & - & Not applicable \\
\hline DCC: VAR(2)-MGARCH(1,1) & Not Achieved & 2.438 & 2.635 & Not applicable \\
\hline DCC: $\operatorname{VAR}(3)-M G A R C H(1,1)$ & Not Achieved & - & - & Not applicable \\
\hline
\end{tabular}

Source: Compiled by the authors 
Table A2 contd.: Model Selection Criteria for VAR-MGARCH models on U.S unconventional monetary policy and macro fundamentals in Nigeria using sub-sample

\begin{tabular}{|c|c|c|c|c|}
\hline \multirow[t]{2}{*}{ Model for EXR -UMP2 } & \multirow[t]{2}{*}{ Convergence Status } & \multicolumn{2}{|c|}{ Selection Criteria } & \multirow[t]{2}{*}{ Rank } \\
\hline & & $S B C$ & $A I C$ & \\
\hline BEKK: VAR(1)-MGARCH(1,1) & Achieved & 2.529 & 5.697 & $1^{s t}$ \\
\hline BEKK: VAR(2)-MGARCH $(1,1)$ & Achieved & 2.609 & 2.817 & $3^{r d}$ \\
\hline BEKK: VAR(3)-MGARCH $(1,1)$ & Achieved & 2.585 & 2.833 & $2^{\text {nd }}$ \\
\hline CC: VAR(1)-MGARCH(1,1) & Not Achieved & 1.420 & 1.568 & Not applicable \\
\hline CC: VAR(2)-MGARCH( $(1,1)$ & Not Achieved & 1.501 & 1.689 & Not applicable \\
\hline CC: VAR(3)-MGARCH(1,1) & Not Achieved & 1.614 & 1.842 & Not applicable \\
\hline DCC: $\operatorname{VAR}(1)-M G A R C H(1,1)$ & Not Achieved & - & - & Not applicable \\
\hline DCC: VAR(2)-MGARCH(1,1) & Not Achieved & - & - & Not applicable \\
\hline DCC: VAR(3)-MGARCH(1,1) & Not Achieved & - & - & Not applicable \\
\hline \multicolumn{5}{|l|}{ Model for INFL-UMP1 } \\
\hline BEKK: VAR(1)-MGARCH(1,1) & Achieved & 6.994 & 6.168 & $3^{r d}$ \\
\hline BEKK: VAR(2)-MGARCH $(1,1)$ & Achieved & 6.088 & 6.296 & $1^{s t}$ \\
\hline BEKK: VAR(3)-MGARCH(1,1) & Achieved & 6.356 & 6.604 & $2^{\text {nd }}$ \\
\hline CC: VAR(1)-MGARCH(1,1) & Not Achieved & 6.637 & 6.522 & Not applicable \\
\hline CC: VAR(2)-MGARCH(1,1) & Not Achieved & 6.104 & 6.294 & Not applicable \\
\hline CC: VAR(3)-MGARCH( $(1,1)$ & Not Achieved & 5.943 & 6.171 & Not applicable \\
\hline DCC: VAR(1)-MGARCH(1,1) & Not Achieved & - & - & Not applicable \\
\hline DCC: VAR(2)-MGARCH(1,1) & Not Achieved & - & - & Not applicable \\
\hline DCC: VAR(3)-MGARCH(1,1) & Not Achieved & - & - & Not applicable \\
\hline \multicolumn{5}{|l|}{ Model for INFL-UMP2 } \\
\hline BEKK: VAR(1)-MGARCH $(1,1)$ & Achieved & 4.828 & 4.995 & $1^{s t}$ \\
\hline BEKK: VAR(2)-MGARCH(1,1) & Achieved & 4.875 & 5.083 & $3^{r d}$ \\
\hline BEKK: VAR(3)-MGARCH $(1,1)$ & Achieved & 4.888 & 5.135 & $5^{t h}$ \\
\hline CC: VAR(1)-MGARCH $(1,1)$ & Not Achieved & 4.886 & 5.034 & $4^{t h}$ \\
\hline CC: VAR(2)-MGARCH(1,1) & Achieved & 4.846 & 5.034 & $2^{\text {nd }}$ \\
\hline CC: VAR(3)-MGARCH(1,1) & Not Achieved & 3.264 & 3.491 & Not applicable \\
\hline DCC: VAR(1)-MGARCH $(1,1)$ & Not Achieved & 4.700 & 4.857 & Not applicable \\
\hline DCC: VAR(2)-MGARCH(1,1) & Not Achieved & 4.869 & 5.067 & Not applicable \\
\hline DCC: VAR(3)-MGARCH(1,1) & Not Achieved & - & - & Not applicable \\
\hline
\end{tabular}

Source: Compiled by the authors 